\title{
WNT signaling underlies the pathogenesis of neuropathic pain in rodents
}

\author{
Yan-Kai Zhang, ${ }^{1}$ Zhi-Jiang Huang, ${ }^{1}$ Su Liu, ${ }^{1,2}$ Yue-Peng Liu,, \\ Angela A. Song, ${ }^{3}$ and Xue-Jun Song ${ }^{1,2}$ \\ 1Department of Neurobiology, Parker University Research Institute, Dallas, Texas, USA. ${ }^{2}$ Neuroscience Research Institute, \\ Peking University, Beijing, China. ${ }^{3}$ Columbia College, Columbia University, New York, New York, USA.
}

\begin{abstract}
Treating neuropathic pain is a major clinical challenge, and the underlying mechanisms of neuropathic pain remain elusive. We hypothesized that neuropathic pain-inducing nerve injury may elicit neuronal alterations that recapitulate events that occur during development. Here, we report that WNT signaling, which is important in developmental processes of the nervous system, plays a critical role in neuropathic pain after sciatic nerve injury and bone cancer in rodents. Nerve injury and bone cancer caused a rapid-onset and long-lasting expression of WNTs, as well as activation of WNT/frizzled/ $\beta$-catenin signaling in the primary sensory neurons, the spinal dorsal horn neurons, and astrocytes. Spinal blockade of WNT signaling pathways inhibited the production and persistence of neuropathic pain and the accompanying neurochemical alterations without affecting normal pain sensitivity and locomotor activity. WNT signaling activation stimulated production of the proinflammatory cytokines IL-18 and TNF- $\alpha$ and regulated the NR2B glutamate receptor and $\mathrm{Ca}^{2+}$-dependent signals through the $\beta$-catenin pathway in the spinal cord. These findings indicate a critical mechanism underlying the pathogenesis of neuropathic pain and suggest that targeting the WNT signaling pathway may be an effective approach for treating neuropathic pain, including bone cancer pain.
\end{abstract}

\section{Introduction}

WNTs are a family of secreted lipid-modified signaling proteins acting as short- or long-range signaling molecules in the regulation of cellular processes such as proliferation, differentiation, migration, and cell polarity during the development of nervous systems as well as cardiac differentiation and development $(1,2)$. A total of 19 members of the human WNT family have been identified. WNT ligands bind to the cysteine-rich domain frizzled (FZ) receptors and FZ coreceptors to activate intracellular signaling cascades. Typical WNT signaling pathways include canonical WNT/ $\beta$-catenin pathways and noncanonical $\beta$-catenin-independent pathways $(1,3-7)$. $\beta$-Catenin is a multifunctional protein that interacts with transcription factors to activate target gene transcription. The noncanonical $\beta$-cateninindependent pathways include the release of intracellular calcium and subsequent activation of calcium-calmodulin-dependent kinase (CaMKII) $(3,4)$. WNTs are expressed in the brain and play critical roles in various nervous system developmental processes $(1,2)$ and in regulating synaptic plasticity $(2,4,8)$. Dysregulation of WNT signaling may be an etiological cause for poor postinjury axon regeneration, oncogenic processes, and certain mental disorders (9-12).

Treatment of neuropathic pain (NP), which is caused by direct nerve injury such as trauma or other forms of stress such as bone cancer, continues to be a major clinical challenge. It is of clinical importance to determine the mechanisms underlying NP as well as to develop medications that can treat it. Despite decades of investigation and numerous implicated processes, the specific cellular and molecular mechanisms underlying NP remain elusive, and clinical approaches for treating NP are limited. We hypothesized that NP-inducing nerve injury may elicit neuronal alterations that

Authorship note: Yan-Kai Zhang, Zhi-Jiang Huang, Su Liu, and Yue-Peng Liu contributed equally to this work.

Conflict of interest: The authors have declared that no conflict of interest exists. Citation for this article: J Clin Invest. 2013;123(5):2268-2286. doi:10.1172/JCI65364. recapitulate events that occur during development. WNT signaling, which is important in the developmental processes of the nervous systems, might be critical to NP development after nerve injury and bone cancer. Bone cancer pain is one of the most common symptoms presented by patients with primary bone sarcomas and predominantly occurs as distant metastases of non-bone cancer. Mechanisms of bone cancer pain may involve a combination of NP and inflammatory pain (IP). We examined roles of WNTs and WNT signaling pathways in the pathophysiology of NP using a well-characterized rat model of chronic constriction injury (CCI) of the sciatic nerves (13) and a mouse model of bone cancer pain induced by tumor cell implantation (TCI) $(14,15)$. As a comparison, inflammatory pain produced by complete Freund's adjuvant (CFA) treatment $(16,17)$ was also tested. The results show that CCI and TCI treatments, respectively, increase expression of WNTs in the dorsal root ganglia (DRG) and spinal cord (SC) and activate WNT/ FZ8/ $\beta$-catenin signaling pathways in the SC. Alterations of these molecules may contribute to the development of NP after CCI and TCI. Spinal blockade of WNT signaling prevents the production and persistence of mechanical allodynia and thermal hyperalgesia after CCI and TCI. WNT signaling in the SC may contribute to NP by stimulating the production of proinflammatory cytokines IL-18 and TNF- $\alpha$ through the WNT/FZ/ $\beta$-catenin pathway.

\section{Results}

CCI increases expression of WNTs and activates WNT/FZ/ $\beta$-catenin in nociceptive pathways. Nerve injury-induced changes in DRG and the SC are critical for NP generation. We began by examining the expression of WNT proteins in the nerve-injured rat DRG and SC $\left(\mathrm{L}_{4}-\mathrm{L}_{5}\right)$. Of the 19 members in the WNT family, WNT3a is a well-characterized activator of the canonical $\beta$-catenin-dependent pathway and the noncanonical $\beta$-catenin-independent pathway, and is widely studied in the development and regeneration of nervous systems $(2,3,5,11,12)$. Our Western blot analysis showed 
A
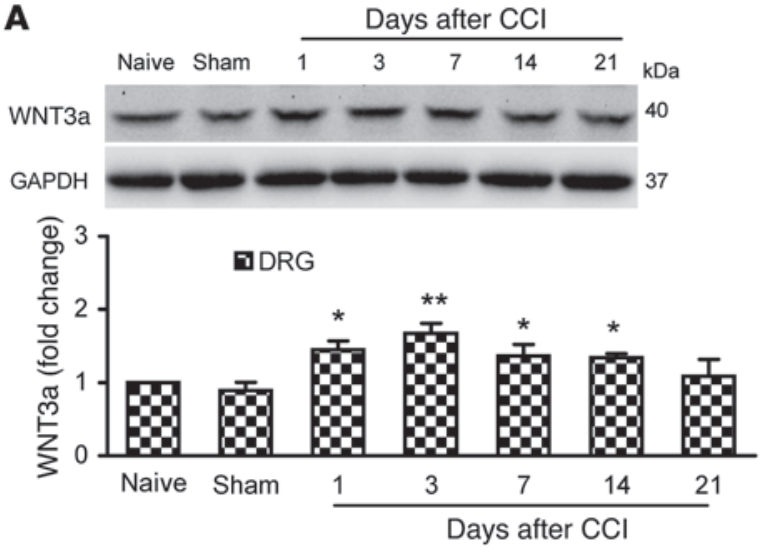

C

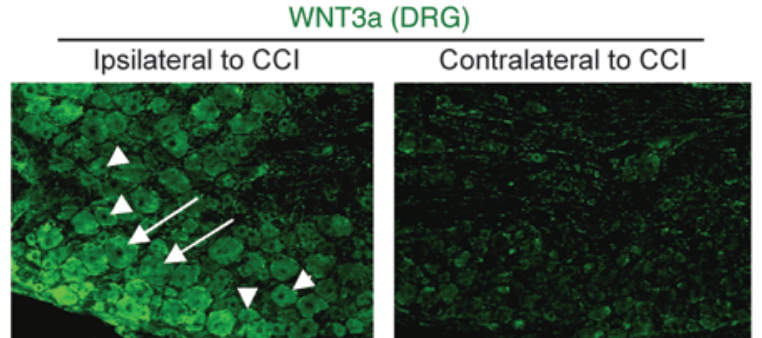

WNT3a

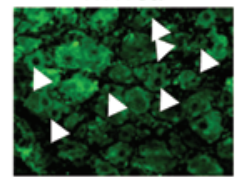

WNT3a

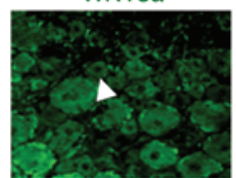

E

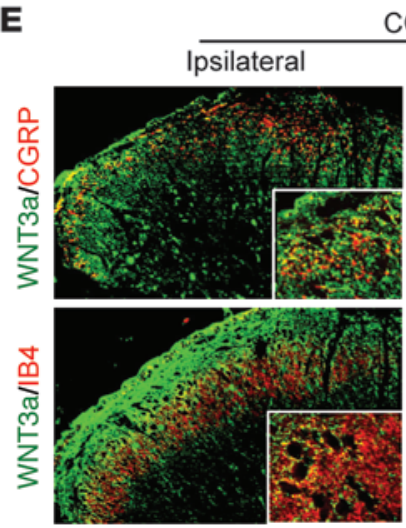

CGRP

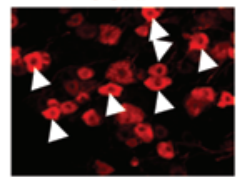

IB4

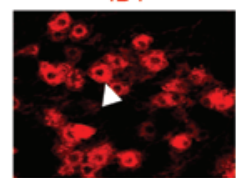

$\mathrm{CCl}$
WNT3a/CGRP

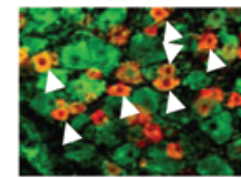

WNT3a/IB4

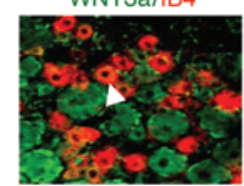

Contralateral
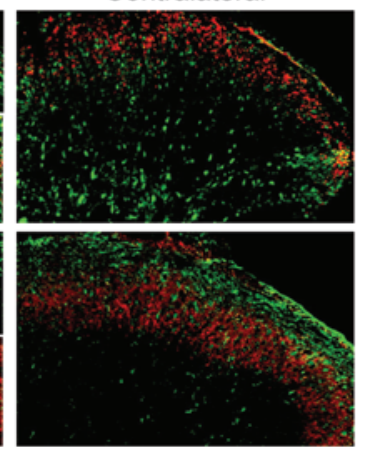

B
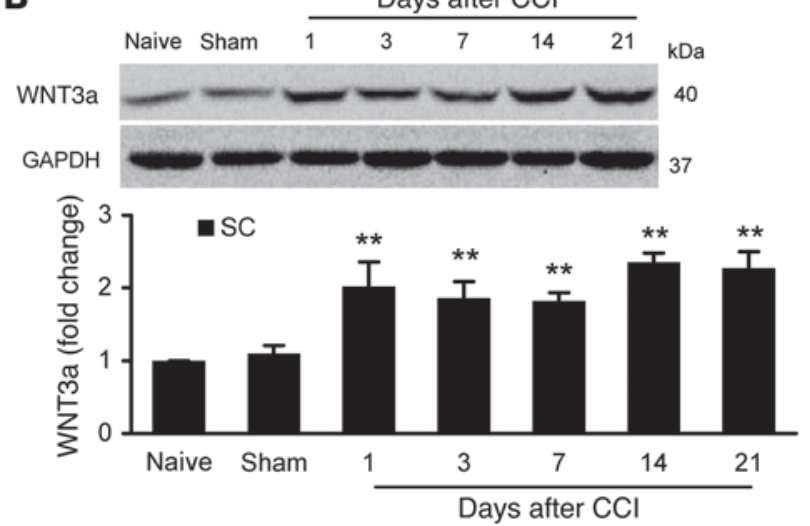

D

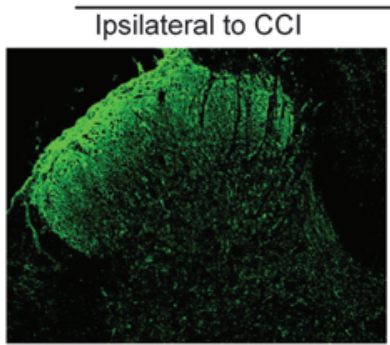

WNT3a/NeuN

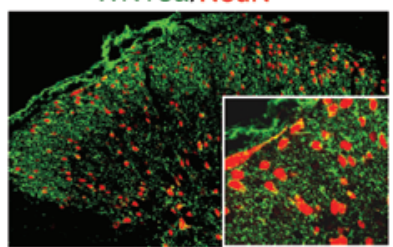

WNT3a/GFAP

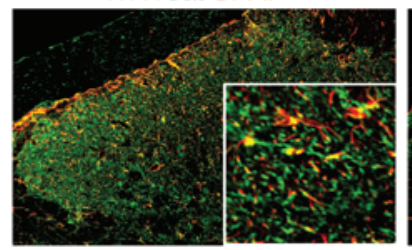

Days after CC

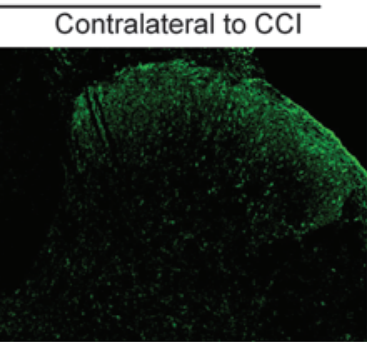

WNT3a/MAP2

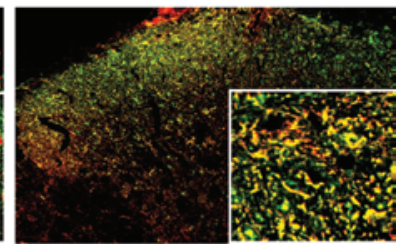

WNT3a/IBA1

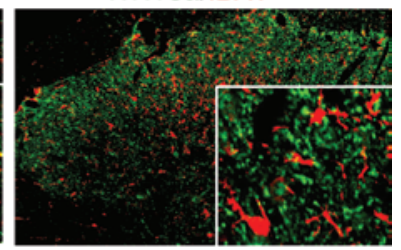

Figure 1

Expression and cellular distributions of WNT3a protein in rat DRG and SC after CCI. (A and B) Western blot showing the time course for WNT3a expression in DRG (A) and SC (B) ( $n=4$ in each). Representative bands are shown on the top; data summary is shown on the bottom. One-way ANOVA, ${ }^{\star} P<0.05,{ }^{\star *} P<0.01$ versus naive and sham. (C) Immunofluorescence showing expression and distribution of WNT3a in DRG neurons. WNT3a was expressed in the large-sized neurons (white arrows) and the small and medium-sized neurons (white arrowheads) ipsilateral to the $\mathrm{CCI}$ (top row). Colocalization of WNT3a with CGRP- and IB4-positive neurons, respectively (middle and bottom rows). (D) Distribution and cellular colocalization of WNT3a in the DH. WNT3a was distributed predominantly in the superficial layers (I-III) (top row). WNT3a was colocalized with neuronal somata (NeuN, red), dendrites (MAP2, red), and astrocytes (GFAP, red), but not with microglial cells (IBA1, red) (middle and bottom rows). (E) Colocalization of WNT3a with CGRP-positive (red) and IB4-positive (red) terminals in the superficial DH. Tissues in (C-E) were collected on day 7 after $\mathbf{C C l}$. Original magnification, $\times 100$ (D, top); $\times 200$ (C, top, and center and bottom rows in D and E); and $\times 400$ (center and bottom rows in $\mathbf{C}$, and inserts in $\mathbf{D}$ and $\mathbf{E}$ ). 
A

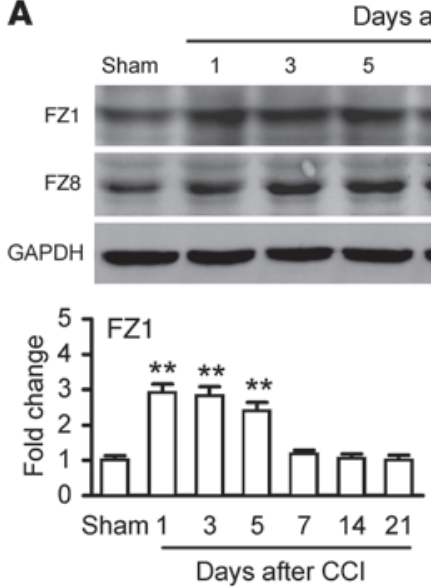

Days after $\mathrm{CCl}$
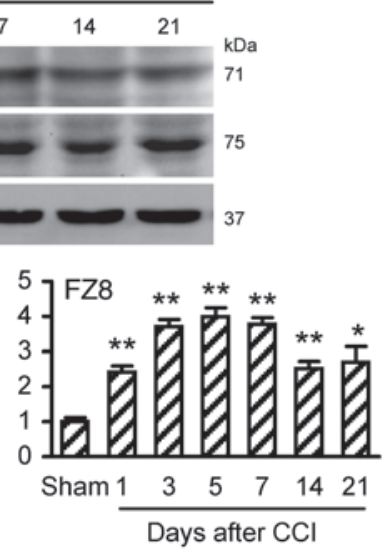

MAP2

c
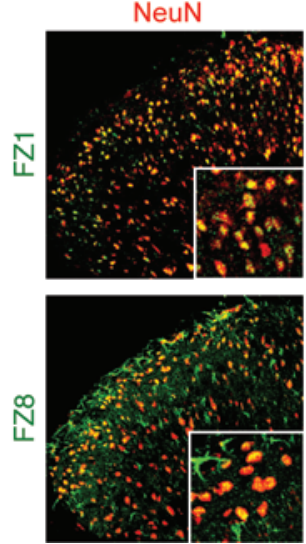
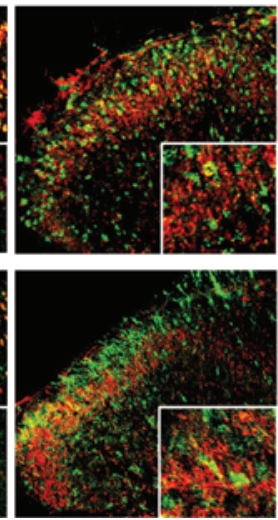

GFAP
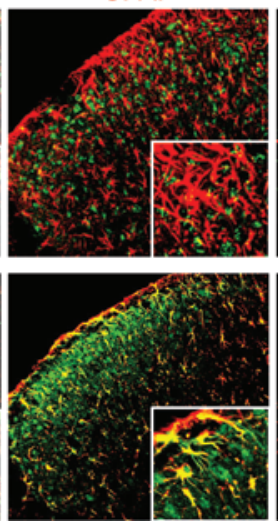

B

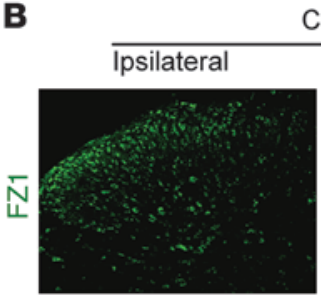

$\mathrm{CCl}$
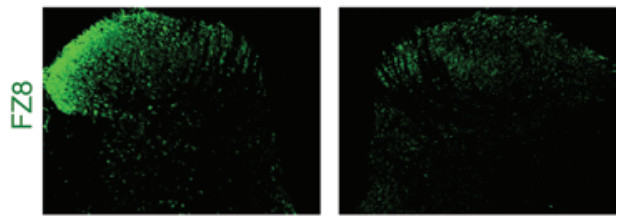

Figure 2

Expression and cellular distributions of FZ1 and FZ8 receptor protein in rat SC after $\mathrm{CCl}$. (A) Western blot analysis showing time course for the expression of FZ1 and FZ8 proteins $(n=5)$. Representative bands are shown on the top; data summary is shown on the bottom. One-way ANOVA, ${ }^{\star} P<0.05,{ }^{* *} P<0.01$ versus sham. (B and $\mathbf{C}$ ) Immunofluorescence showing expression and distribution of FZ1 and FZ8 (green) in the DH (B) and their colocalization with neuronal somata (NeuN, red), dendrites (MAP2, red), and astrocytes (GFAP, red), as well as microglial cells (IBA1 red) in the superficial DH ipsilateral to the $\mathrm{CCl}(\mathbf{C})$. Tissues were collected on day 1 for $\mathrm{FZ1}$ and day 7 for $\mathrm{FZ8}(\mathbf{B}$ and $\mathbf{C})$, respectively, after $\mathrm{CCl}$. Original magnification, $\times 100(B), \times 200(C)$, and $\times 400$ (insert in C).

that CCI produced a rapid-onset (within 1 day) and long-lasting (greater than 21 days) increase in the expression of WNT3a protein in DRG and SC. In DRG, WNT3a peaked at 1 to 7 days, started decreasing from 7 days, and recovered to the control level at 21 days after CCI (Figure 1A). In SC, WNT3a was maintained at a high level from 1 to 21 days, the last examination day, after CCI (Figure 1B). mRNA levels of the 19 members of the WNT family in the SC were also detected by RT-PCR and some by RT-PCR and quantitative RT-PCR (qRT-PCR). Wnt3a, Wnt1, Wnt2, Wnt4, Wnt5b, and $W n t 8 b$ were continuously or temporally increased, while the others were slightly decreased or unchanged 1-10 days after CCI (Supplemental Figure 1; supplemental material available online with this article; doi:10.1172/JCI65364DS1). These results indicate that WNT3a may be initially increased in both DRG and the SC. WNT3a in the SC may originate from the SC and be released from central terminals of DRG neurons.

We then examined distributions of WNT3a in subpopulations of DRG and the dorsal horn (DH) neurons. In DRG, the increased WNT3a protein immunoreactivity was distributed in the 3 categories of neurons: large-sized, medium-sized, and small neurons.
However, strong staining of WNT3a was predominantly distributed in the nociceptive small- and medium-sized neurons $\left(\chi^{2}\right.$ test, $P<0.01$ ) (Figure 1C and Supplemental Figure 2A). In the small neurons, strong staining of WNT3a was more significantly colocalized with the peptidergic calcitonin gene-related peptide (CGRP) and less so with the nonpeptidergic isolectin B4 (IB4) nociceptive neurons ipsilateral to the CCI $\left(\chi^{2}\right.$ test, $\left.P<0.01\right)$ (Figure $1 \mathrm{C}$ and Supplemental Figure $2 \mathrm{~B})$. After nerve injury, it is recognized that the hypersensitized, large-sized fibers may contribute to the development of allodynia, while the small and medium-sized fibers contribute to hyperalgesia. Thus, the increased expression and distribution of WNT3a in the small and medium-sized, as well as the large-sized DRG neurons after CCI may support our hypothesis that WNT3a contributes to the development of both hyperalgesia and allodynia. In the SC, the increased WNT3a protein immunoreactivity was distributed predominantly in the superficial layers (laminae I-II) of the DH ipsilateral to the CCI. WNT3a immunoreactivity was colocalized greatly with neuronal somata (NeuN) and dendrites (MAP2), as well as with astrocytes (GFAP), but not with microglial cells (IBA1) (Figure 1D). WNT3a 
A
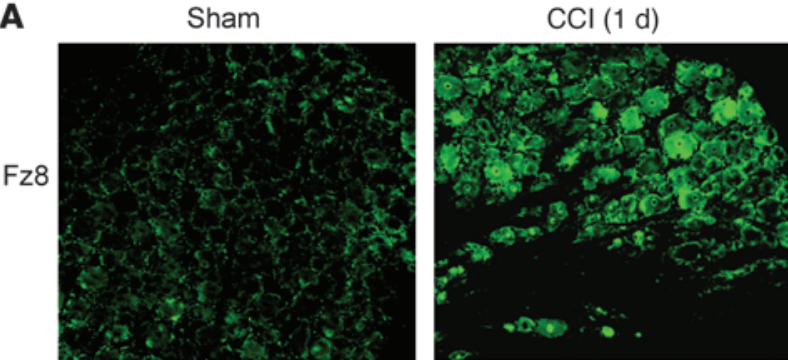

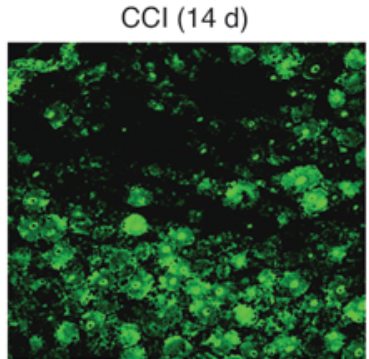

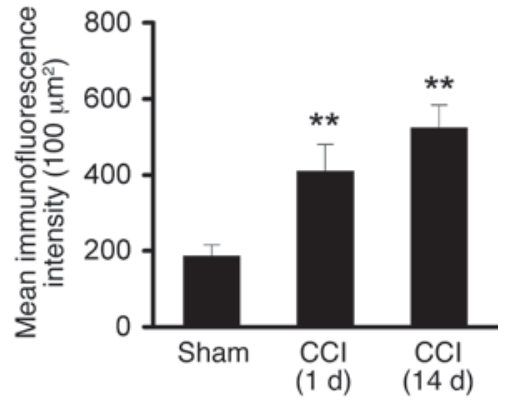

B
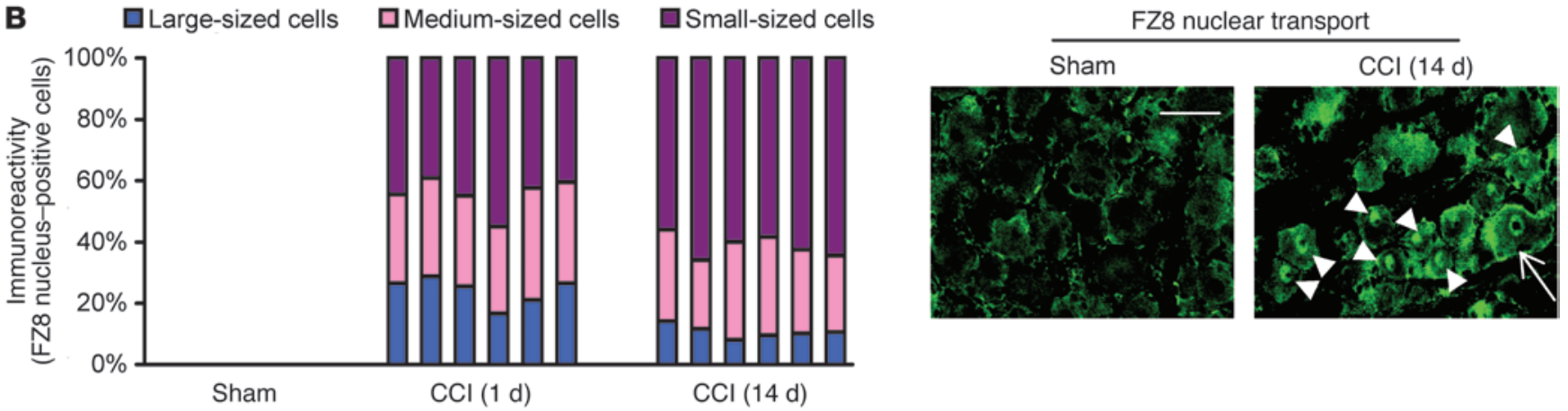

C

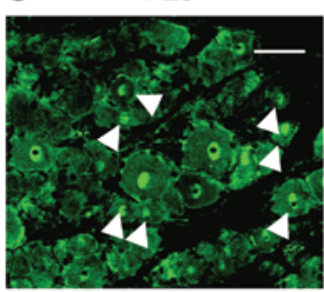

FZ8

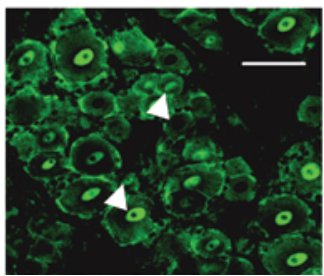

CGRP

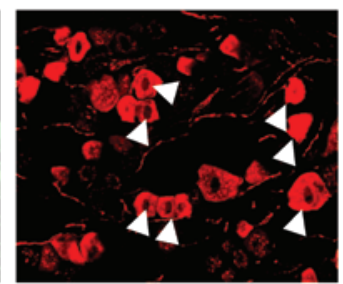

IB4

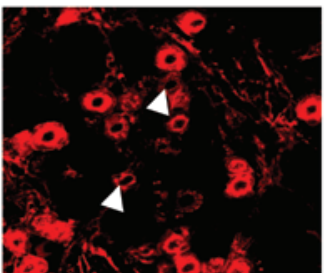

WNT3a/CGRP

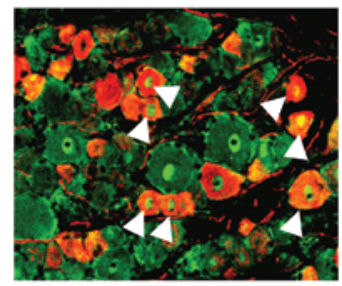

WNT3a/IB4

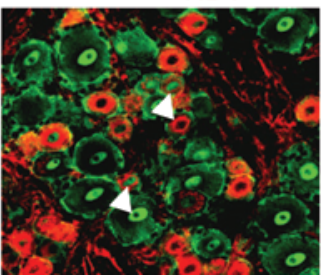

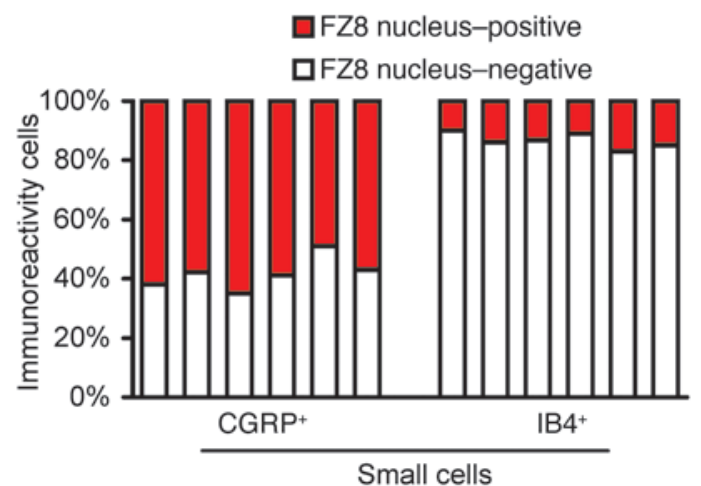

Small cells

Figure 3

Alteration and distribution of immunofluorescence staining of FZ8 protein in rat DRG cells after $\mathrm{CCl}$. (A) Examples of FZ8 immunostaining in sham-operated and CCl-treated DRG. Original magnification, $\times 200$. Mean immunofluorescence intensity (right). "CCl (1 d)" and "CCl (14 d)" represent 1 day and 14 days, respectively, after $\mathrm{CCl}$ treatment. One-way ANOVA, ${ }^{\star \star} P<0.01$ versus sham. (B) Proportion of cells with FZ8 nuclear transport. No nuclear transport was seen in sham DRG. In CCl-treated DRG, nuclear transport was primarily seen in the small cells. $X^{2}$ test, $P<0.01$, small versus medium-sized $(\mathrm{CCl} 14 \mathrm{~d})$ and large-sized cells $(\mathrm{CCl} 1 \mathrm{~d}$ and $\mathrm{CCl} 14 \mathrm{~d}) ; P<0.05$ small versus medium-sized and mediumversus large-sized cells on $\mathrm{CCl}$ day 14. Example of confocal images showing FZ8 nuclear transport on CCI day 14, but not in sham DRG (right). FZ8 nuclear transport was seen mostly in the small and medium-sized neurons (arrowheads) and a small amount was seen in the large-sized neurons (arrow). (C) FZ8 nuclear transport in CGRP- and IB4-positive cells. Tissues were collected on CCI day 14. Examples of confocal images (left). Arrowheads indicate CGRP- and IB4-positive cells with FZ8 nuclear transport. Data summary is shown on the right. FZ8 nuclear transport predominantly occurred in the CGRP-positive, but not in the IB4-positive small cells ( $X^{2}$ test, $\left.P<0.01\right)$. Scale bars: $50 \mu \mathrm{m}$ (B and C).

immunoreactivity was also found to be increased after CCI in both CGRP and IB4 nociceptive terminals within the DH (Figure 1E), which further confirmed WNT3a expression in the small DRG neurons (see Figure 1C). These results demonstrate that WNT signaling was broadly activated in the nociceptive pathways in DRG neurons as well as in DH neurons and astrocytes after CCI.
Released WNTs from the primary afferent terminals and the DH bind to their $\mathrm{FZ}$ receptors in the postsynaptic neurons and activate intracellular signaling cascades. After CCI, the expression of FZ receptor family members FZ1 and FZ8 in the SC was significantly and rapidly increased within 1 day, lasting for 5 days for FZ1, and up to 21 days for FZ8 (Figure 2A). Increased levels of $F z 1, F z 8$, as 


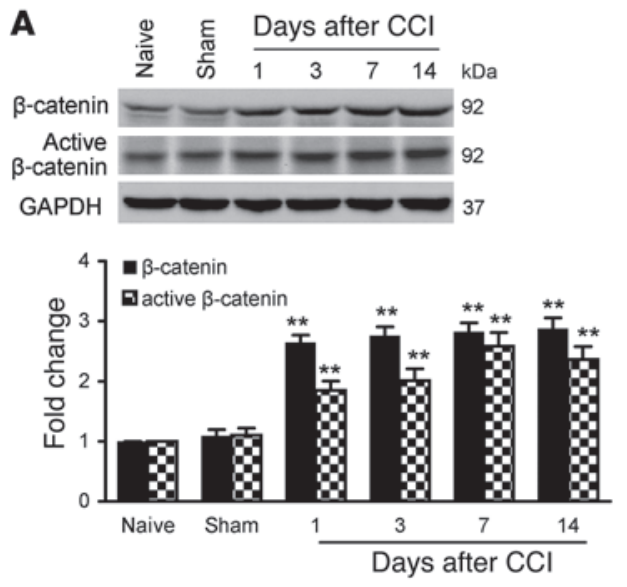

B

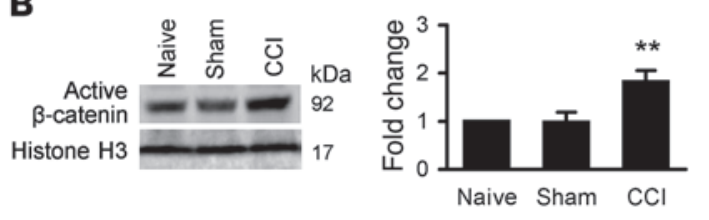

C
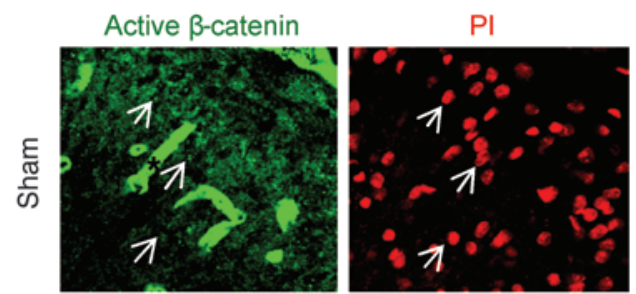

Active $\beta$-catenin/PI
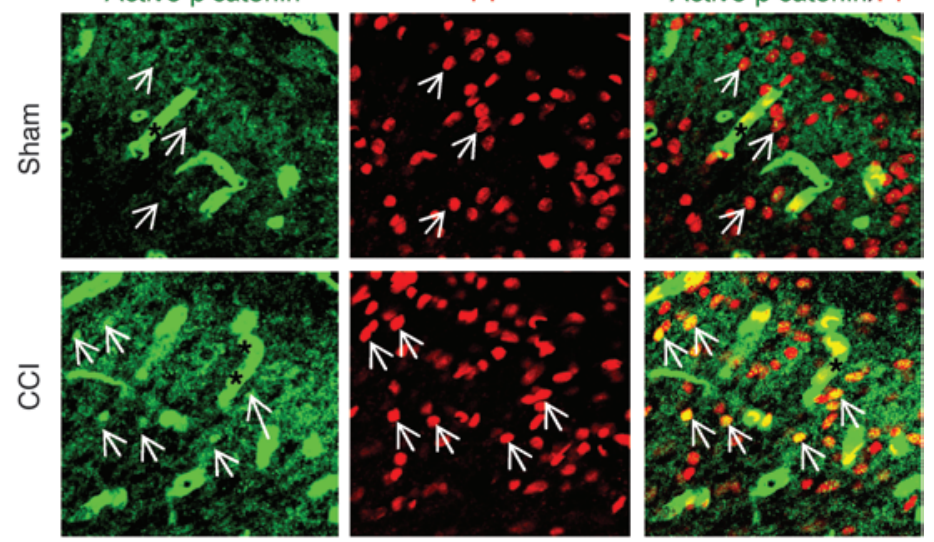

D

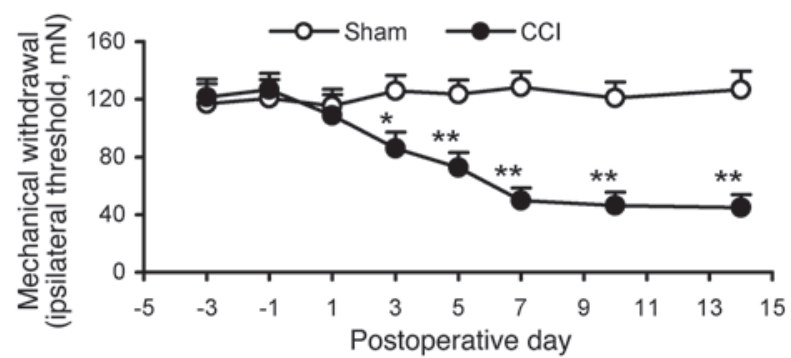

\section{Figure 4}

Activation of $\beta$-catenin in rat SC after CCI treatment. (A) Western blot analysis showing time course for the expression of $\beta$-catenin and active $\beta$-catenin $(n=4)$. Representative bands are shown at the top; data summary is shown at the bottom (mean \pm SEM). One-way ANOVA, ${ }^{* *} P<0.01$ versus naive and sham. (B) Western blot analysis showing active $\beta$-catenin nuclear protein expression $(n=4)$. Histone-H3 was used as the loading control. Data summary is shown on the right. One-way ANOVA, ${ }^{\star \star} P<0.01$ versus naive and sham. (C) Confocal images showing active $\beta$-catenin expression and its transport into the cellular nucleus $(\mathrm{PI})$ in the superficial $\mathrm{DH}$. Arrows indicate some of the nuclear transport of active $\beta$-catenin. Note that the bold, long-shaped green stains are $\beta$-catenin in blood vessels (indicated by asterisks). Tissues were taken on day 7 after $\mathrm{CCl}$. Original magnification, $\times 400$. (D) CCl-induced mechanical hypersensitivity manifested as a lowered threshold of mechanical withdrawal. Eight rats were included in each group. Two-way ANOVA, ${ }^{*} P<0.05,{ }^{\star \star} P<0.01$ versus sham.

well as $F z 3, F z 4, F z 5$, and $F z 10$ mRNAs were also detected in the SC at different time points after CCI (Supplemental Figure 3). The increased immunoreactivity of FZ1 and FZ8 in the DH was predominantly distributed in the superficial layers of the DH (laminae I-III) ipsilateral to the CCI (Figure 2B). FZ1, which increased over 1 to 5 days, was colocalized with neurons and dendrites, but not with astrocytes or microglial cells (Figure 2C and Supplemental Figure 4A). Increased FZ8 over 1 to 21 days was colocalized with neurons and dendrites, substantially so with astrocytes, but not with microglial cells (Figure 2C and Supplemental Figure 4B). These results indicate that after CCI, both FZ1 and FZ8 receptors in the $\mathrm{DH}$ neurons were activated in the early phase. However, in the late phase, only FZ8 was persistently activated - moderately in neurons and substantially in astrocytes.

Given that CCI caused a substantial increase of WNT3a in DRG and the $\mathrm{DH}$, as well as $\mathrm{FZ}$ receptors in the $\mathrm{DH}$, we continued to investigate possible alterations of $\mathrm{FZ}$ receptor expression and distribution in the presynaptic DRG somata following CCI treatment, although WNTs released from the primary afferent terminals and the $\mathrm{DH}$ neurons bind to their $\mathrm{FZ}$ receptors in the postsynaptic neurons in the DH and activate intracellular signaling cascades. The results showed that FZ8 was expressed at low immunofluorescence intensity in the sham-operated DRG cells and was greatly increased in the nerve-injured DRG examined at 1 and 14 days after CCI (Fig- ure 3A). CCI also caused large amounts of FZ8 nuclear transport. FZ8 nuclear transport occurred with significantly greater abundance in the small and medium-sized neurons $(\sim 80 \%)$ compared with the large-sized neurons $(\sim 20 \%)\left(\chi^{2}\right.$ test, $\left.P<0.01\right)$ (Figure $\left.3 \mathrm{~B}\right)$. In the small neurons, FZ8 nuclear transport was predominantly seen in the CGRP-positive ( $60 \%)$ neurons, with a few in the IB4-positive $(\sim 15 \%)$ neurons $\left(\chi^{2}\right.$ test, $\left.P<0.01\right)$ (Figure $\left.3 \mathrm{C}\right)$. In contrast, FZ1 expression, which was at a low level in sham-operated DRG, was not significantly changed by CCI treatment (Supplemental Figure 5). FZ1 expression was distributed evenly in the 3 categories of DRG neurons as well as in the CGRP- and IB4-positive small neurons. FZ1 nuclear transport was not observed in any of the cells examined (Supplemental Figure 5, A and C). In addition, FZ8, but not FZ1, was expressed in certain satellite glial cells that mostly surround the large-sized neurons; these FZ8 colocalized satellite glial cells showed no glial nuclear transport (Supplemental Figure 6). These results suggest that WNTs may function through FZ8, but not FZ1, in DRG neurons following nerve injury.

Binding of the released WNTs to the FZ receptors causes activation of $\mathrm{WNT} / \beta$-catenin signaling in the postsynaptic neurons. Cytoplasmic $\beta$-catenin accumulates and is eventually imported into the nucleus, where it serves as a transcriptional coactivator of $\mathrm{T}$ cell factor/lymphocyte-enhancer factor (TCF/LEF) family transcription factors $(3,4,18)$. CCI caused a rapid-onset (within 1 
A
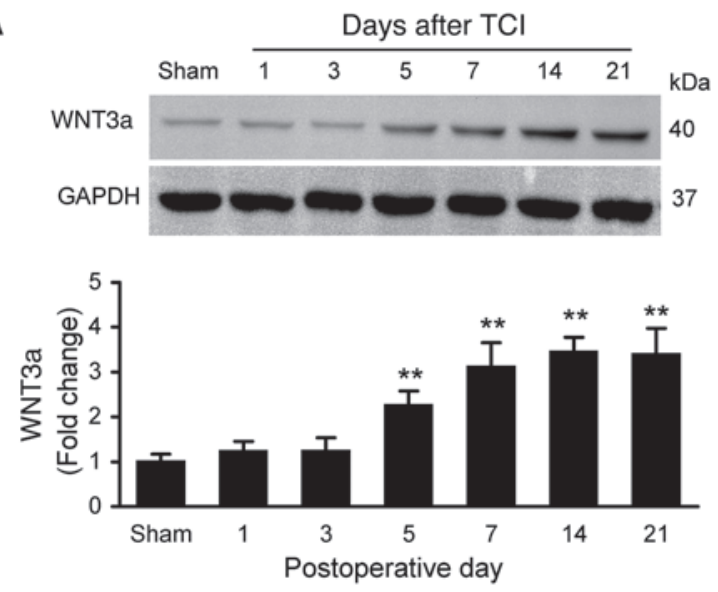

C
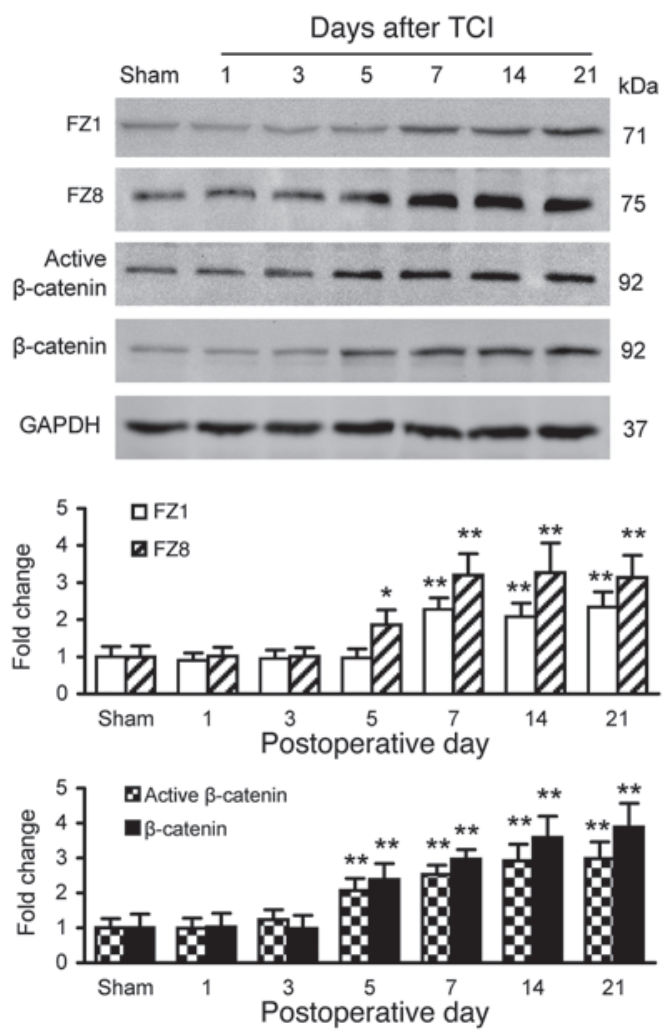

B

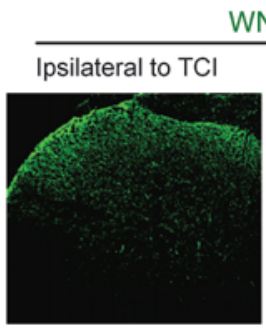

WNT3a/MAP2

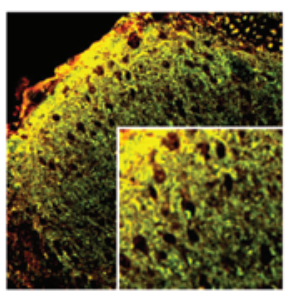

WNT3a

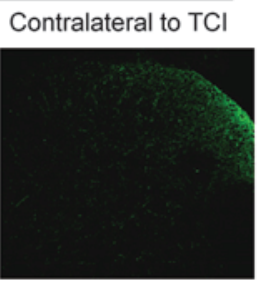

WNT3a/GFAP

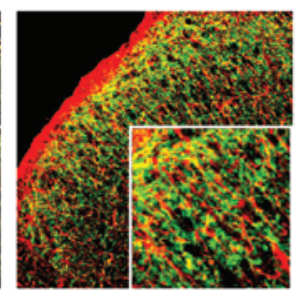

WNT3a/NeuN

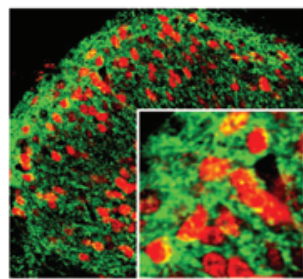

WNT3a/IBA1

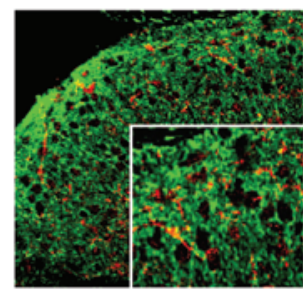

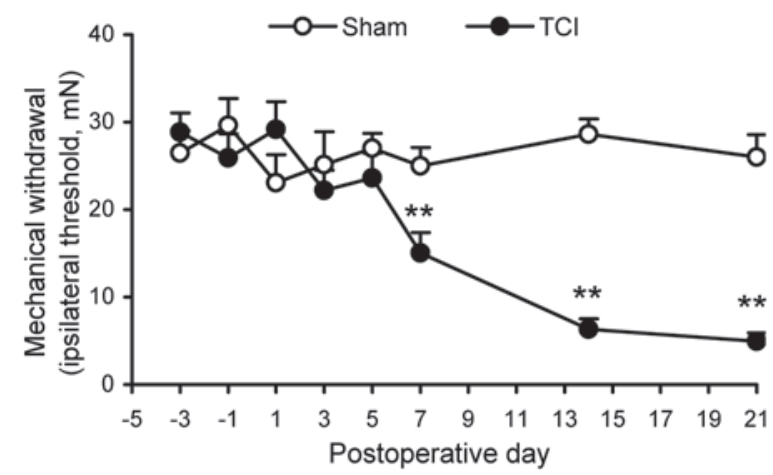

\section{Figure 5}

Expression of WNT3a, FZ1, FZ8, and $\beta$-catenin protein and cellular distributions of WNT3a in mouse SC after TCl treatment. (A) Western blot analysis showing time course for the expression of WNT3a ( $n=4$ in each). Representative bands are shown on the top; data summary is shown on the bottom. One-way ANOVA, ${ }^{* *} P<0.01$ versus sham. (B) Immunofluorescence showing expression of WNT3a protein (green) in the superficial DH and its cellular colocalization with neuronal somata (NeuN, red), dendrites (MAP2, red), and astrocytes (GFAP, red), as well as microglial cells (IBA1 red). Tissues were collected 14 days after TCI. Original magnification, $\times 200$ (top row, left), $\times 400$ (the rest), and $\times 600$ (inserts). (C) Western blot analysis showing time course for the expression of FZ1, FZ8, active $\beta$-catenin, and $\beta$-catenin $(n=4$ in each) following TCl treatment. One-way ANOVA, ${ }^{\star} P<0.05,{ }^{*} P<0.01$ versus sham. (D) TCl-induced mechanical hypersensitivity manifested as a lowered threshold of mechanical withdrawal. Eight rats were included in each group. Two-way ANOVA, ${ }^{* *} P<0.01$ versus sham.

day) and long-lasting (21 days, the last examination day) increase in both phosphorylated and dephosphorylated active $\beta$-catenin expression in the SC (Figure 4A). This increased expression of active $\beta$-catenin was also significantly increased in the nuclear protein (Figure 4B). Confocal images further show that CCI induced increased expression of active $\beta$-catenin and its transportation into the cellular nucleus in the superficial DH (Figure 4C). These results indicate that CCI treatment can activate the WNT/ 

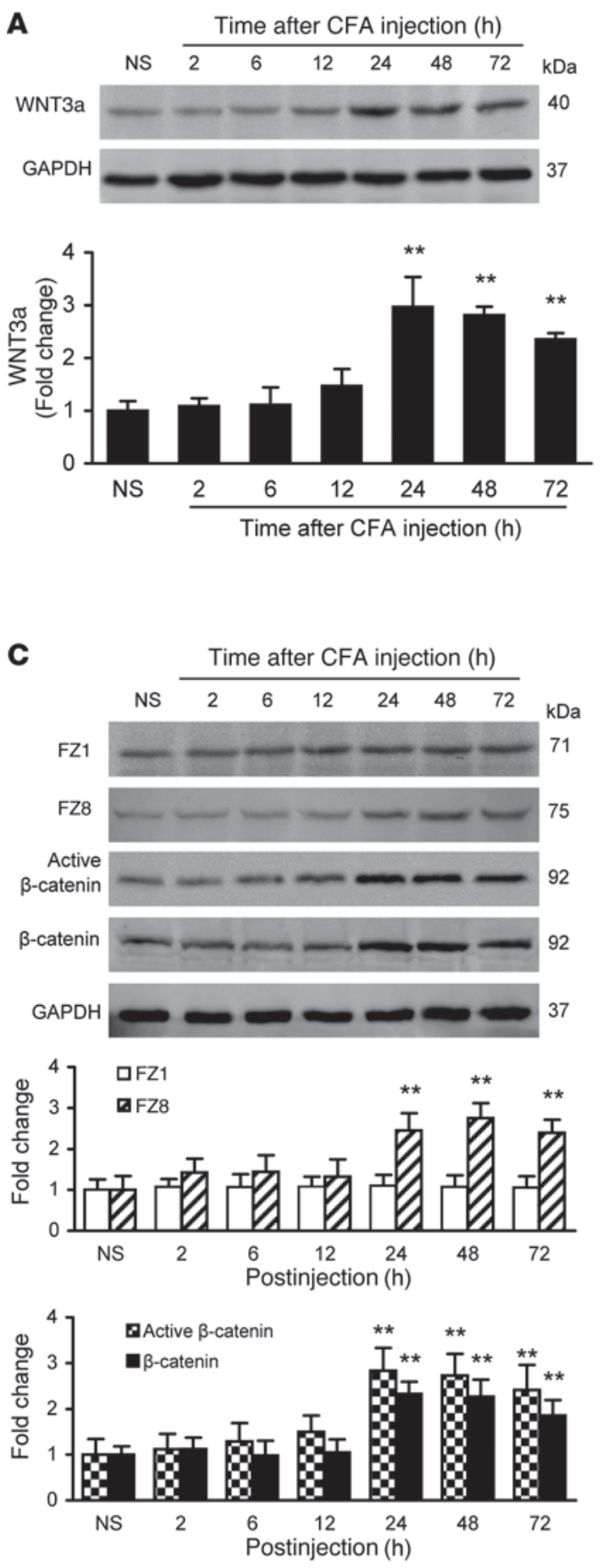

FZ/ $\beta$-catenin signaling pathway in the SC. However, in DRG, CCI treatment caused neither alteration of $\beta$-catenin expression nor $\beta$-catenin nuclear transport (Supplemental Figure 7A, far left col$\mathrm{umn}$ ), indicating that WNT signaling activity does not result in the activation of $\beta$-catenin. These results suggest that, after nerve injury, WNT signaling may function in a $\beta$-catenin-independent pathway in presynaptic DRG neurons, unlike in the SC.

CCI-induced mechanical allodynia and thermal hyperalgesia have been well characterized and are detectable approximately 3 days after CCI. An example of CCI-induced mechanical allodynia
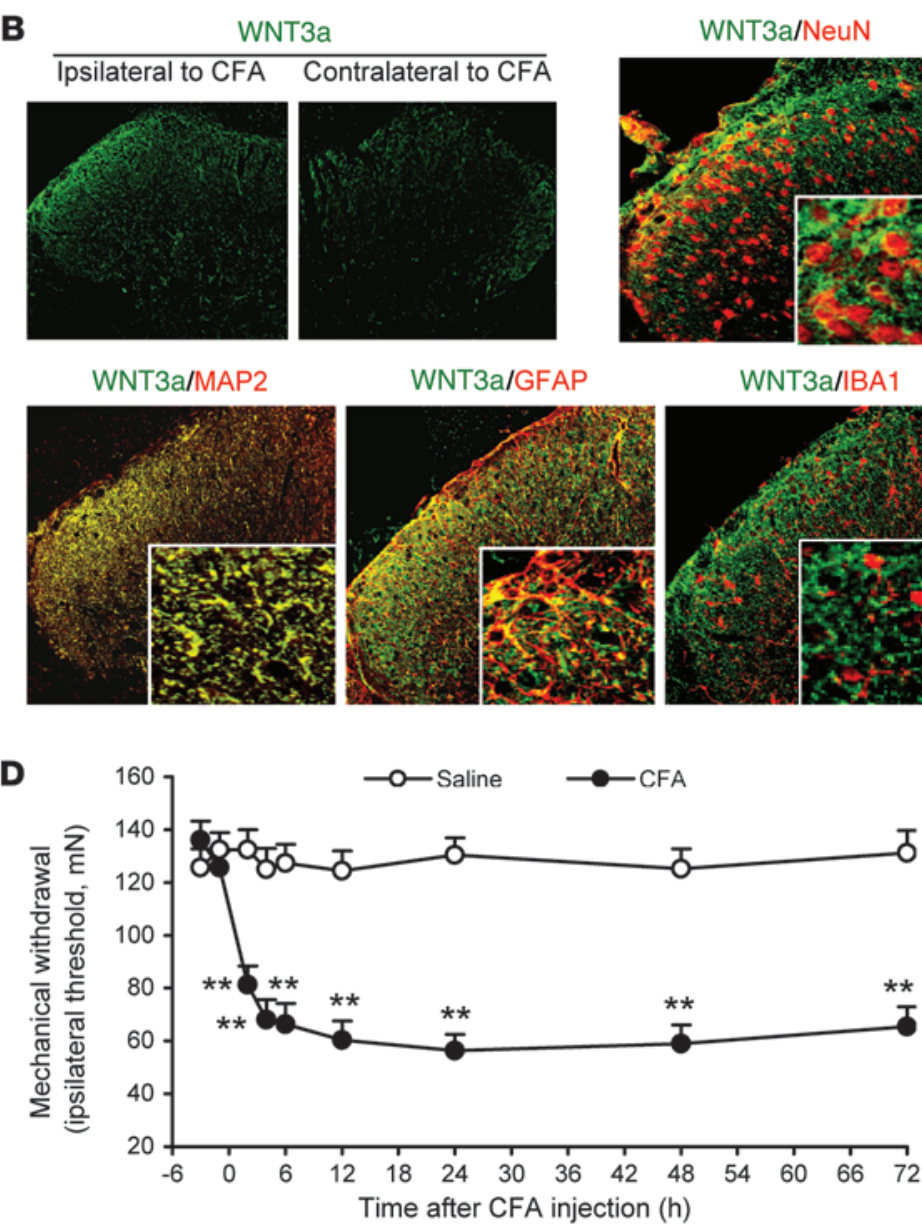

Figure 6

Expression of WNT3a, FZ1, FZ8, and $\beta$-catenin protein and cellular distributions of WNT3a in rat SC after CFA treatment. (A) Western blot analysis showing time course for the expression of WNT3a $(n=4$ in each). Representative bands are shown on the top; data summary is shown on the bottom. One-way ANOVA, ${ }^{* \star} P<0.01$ versus normal saline (NS). (B) Immunofluorescence showing expression of WNT3a protein (green) in the superficial DH and its cellular colocalization with neuronal somata (NeuN, red), dendrites (MAP2, red), and astrocytes (GFAP, red), as well as microglial cells (IBA1 red). Tissues were collected 24 hours after CFA. Original magnification, $\times 100$ (top row, left), $\times 200$ (the rest), and $\times 400$ (inserts). (C) Western blot analysis showing time course for the expression of FZ1, FZ8, active $\beta$-catenin, and $\beta$-catenin $(n=4$ in each) following CFA treatment. One-way ANOVA, ${ }^{*} P<0.01$ versus NS. (D) CFA-induced mechanical hypersensitivity manifested as a lowered threshold of mechanical withdrawal. Eight rats were included in each group. Two-way ANOVA, ${ }^{\star \star} P<0.01$ versus sham. 

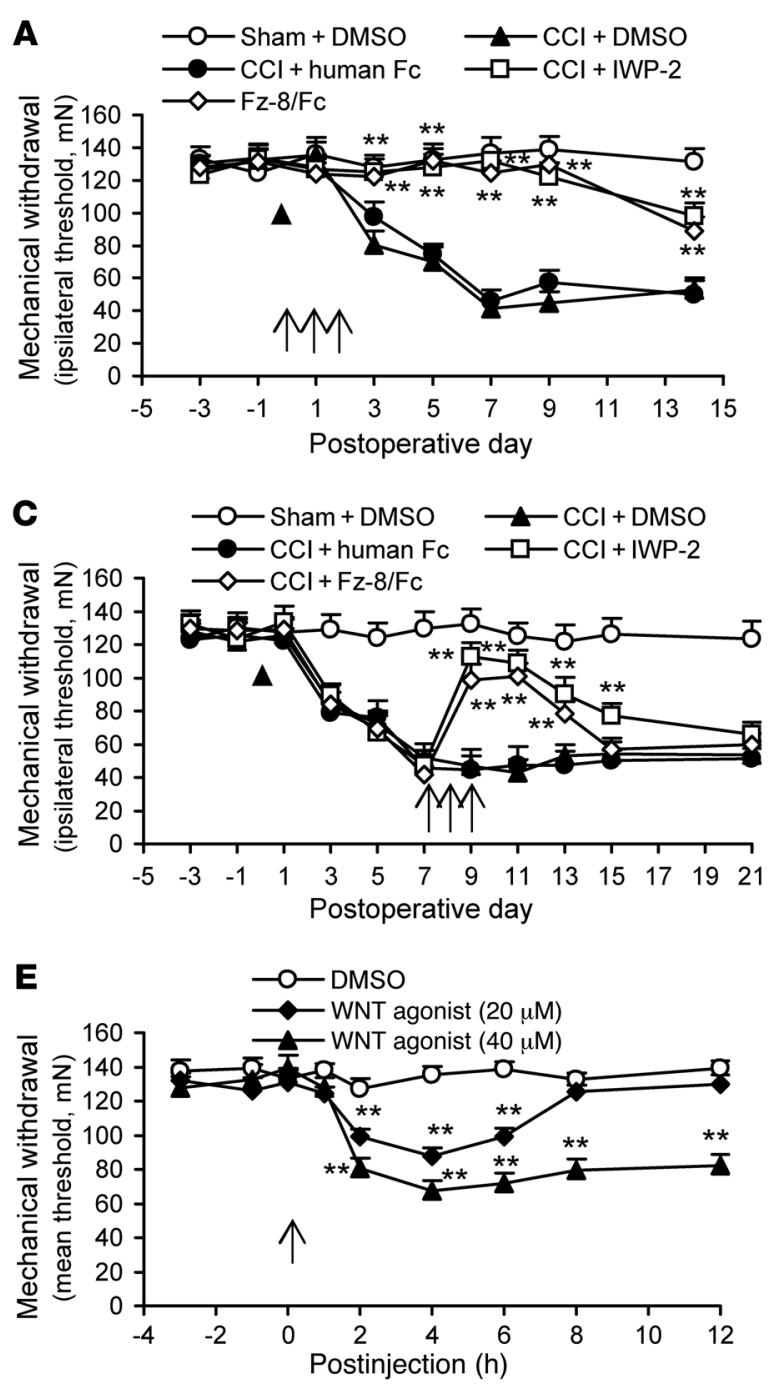
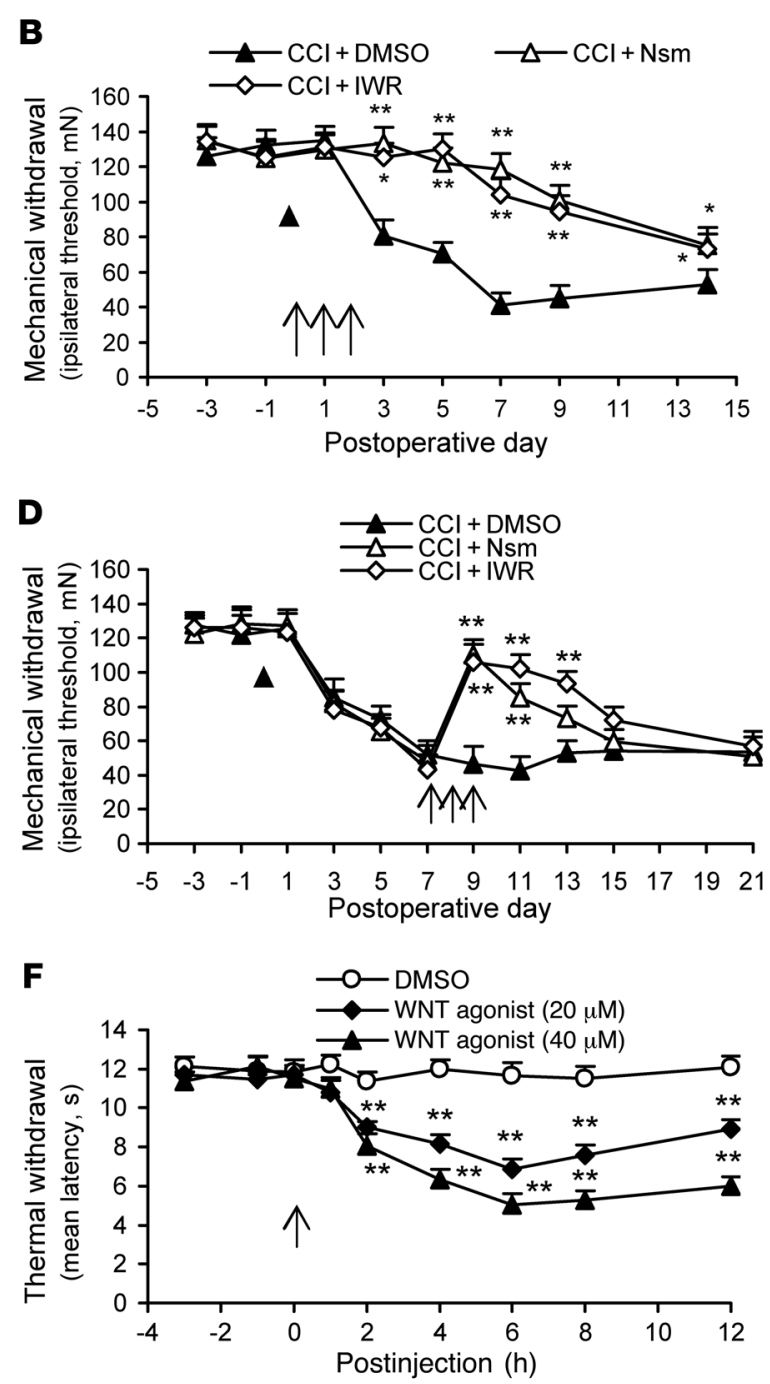

Figure 7

Activation of WNT signaling contributes to the development of NP after CCl treatment. (A-D) Effects of administration of WNT production inhibitor IWP-2, WNT scavenger Fz-8/Fc ( $\mathbf{A}$ and $\mathbf{C}$ ), as well as WNT/ $\beta$-catenin pathway inhibitors IWR and Nsm (B and $\mathbf{D}$ ) on the production and persistence of mechanical allodynia in $\mathrm{CCI}$ rats. (E and $\mathbf{F})$ Administration of WNT agonist-induced mechanical $(\mathbf{E})$ and thermal $(\mathbf{F})$ hypersensitivity in naive rats. Drug doses (i.t., in a volume of $20 \mu \mathrm{l})$ : IWP-2 (20 $\mu \mathrm{M})$; Fz-8/Fc $(4 \mu \mathrm{g})$; human Fc $(4 \mu \mathrm{g})$; DMSO (1\%); IWR (5 $\mu \mathrm{M})$; Nsm (1 mM); and WNT agonist $(20$ and $40 \mu \mathrm{M})$. The human Fc and DMSO were used as controls. Each administration is indicated by an arrow on the corresponding time point. Eight rats were included in each group. Two-way ANOVA was used in A-F, and an individual Student's $t$ test was used to test the specific difference between the data point before drug administration and each of the data points after drug administration $(\mathbf{C}$ and $\mathbf{D})$. ${ }^{*} P<0.05$, ${ }^{\star \star} P<0.01$ versus $\mathrm{CCl}+\mathrm{DMSO}$ and/or $\mathrm{CCl}+$ human $\mathrm{Fc}(\mathbf{A}-\mathbf{D})$ and DMSO (E and $\left.\mathbf{F}\right)$, respectively. Black triangles indicate $\mathrm{CCl}$ surgery $(\mathbf{A}-\mathbf{D})$.

correlated with the time course for changes in pain behaviors after CCI, suggesting that WNT3a/FZ8/ $\beta$-catenin signaling in the SC may contribute to the persistence of NP. In contrast, FZ1 expression was rapidly, but transiently, upregulated over the course of 1 to 5 days after CCI, and quickly recovered, suggesting that FZ1 activation may be correlated with or contribute to the production, but not the persistence, of NP.

TCI increases expression of WNTs and activates WNT/FZ/ $\beta$-catenin pathways. Given that WNT expression was increased and WNT/FZ/ $\beta$ catenin signaling pathways were activated after CCI treatment, we examined whether WNT/FZ/ $\beta$-catenin signaling pathways could also be activated after TCI treatment, which caused bone cancer and the subsequent bone cancer pain in animals that mimics the intrac- table cancer pain in patients. Our Western blot analysis showed that after TCI treatment and during the development and persistence of bone cancer pain, the expression of WNT3a was rapidly and significantly increased in the ipsilateral SCs of the experimental mice. The increase in WNT3a expression started on day 5, peaked at 7 to 14 days, and was maintained at a high level until the last examination on day 21 (Figure 5A). The increased WNT3a protein immunoreactivity was distributed predominantly in the superficial layers of the DH (laminae I-II) ipsilateral to the TCI site. WNT3a immunoreactivity was colocalized with neuronal somata and dendrites, astrocytes, and occasionally in small amounts with microglial cells (Figure 5B). Similarly to WNT3a, expression in the SC of the WNT receptor FZ8, as well as phosphorylated $\beta$-catenin and dephospho- 
A
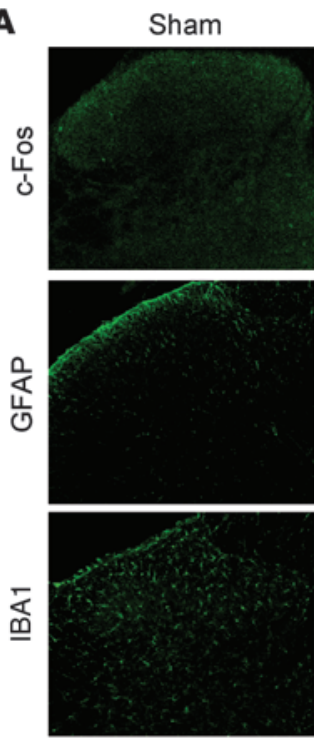

B

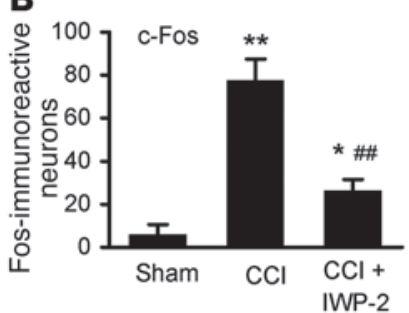

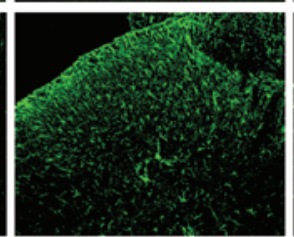

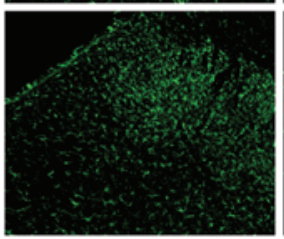

$\mathrm{CCl}$
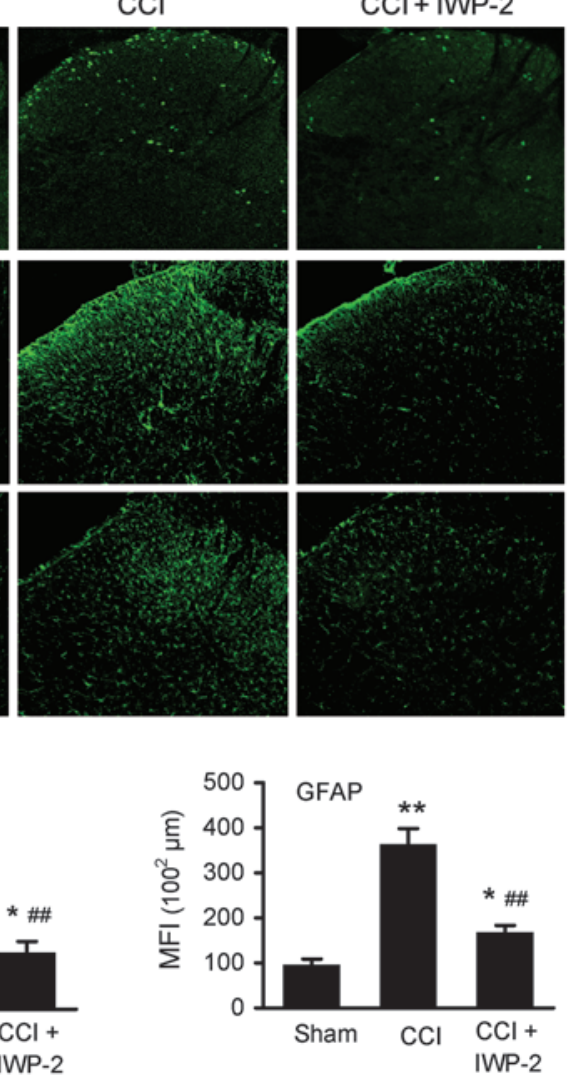
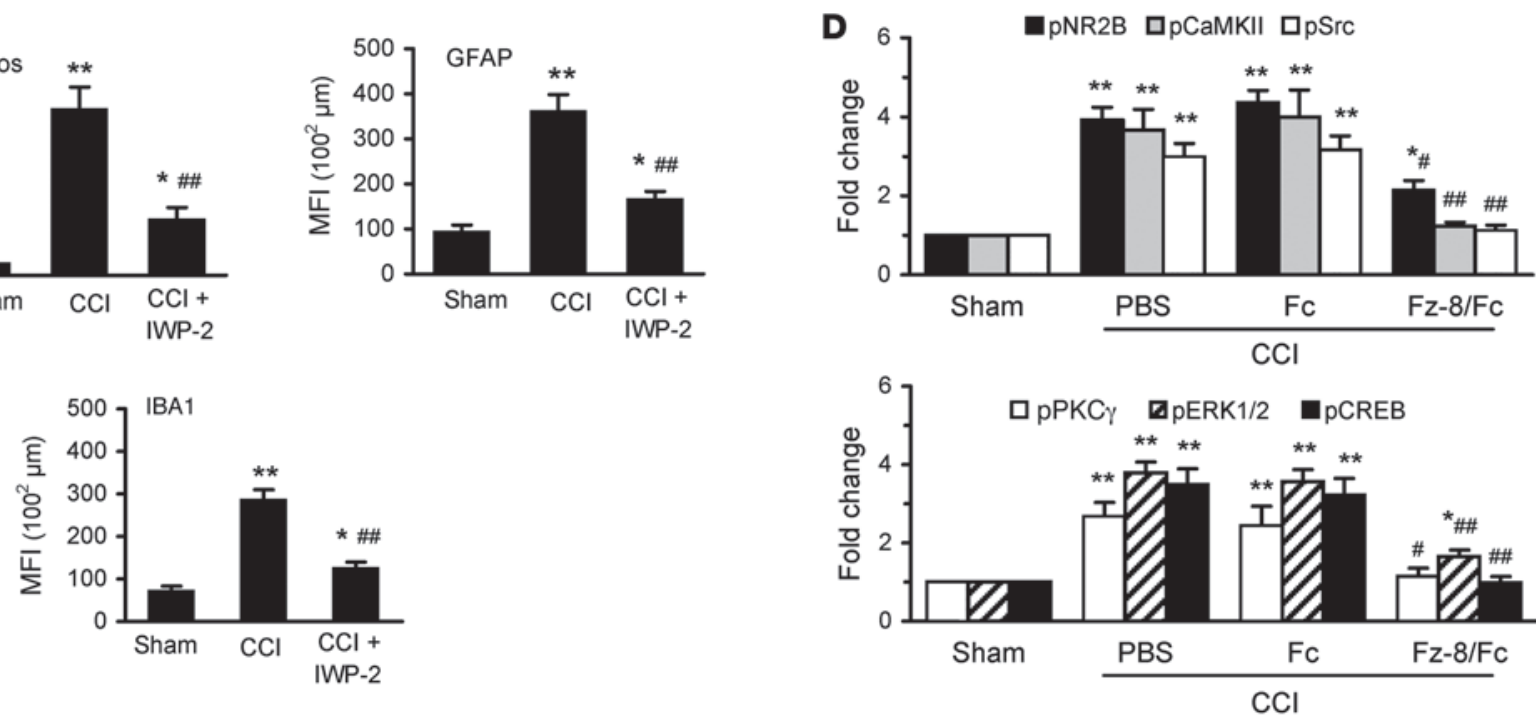

\section{Figure 8}

Intrathecal administration of WNT production inhibitor IWP-2 or WNT scavenger Fz-8/Fc suppresses neurochemical signs of NP as well as NR2B and the subsequent $\mathrm{Ca}^{2+}$-dependent signals in rat SC. (A) Confocal images showing inhibitory effects of IWP-2 on induction of c-Fos, activation of astrocytes (GFAP), and microglial cells (IBA1). Original magnification, $\times 200$. (B) Data summary of A. IWP-2 (20 $\mu$ M, i.t.) was given once a day on postoperative days 7,8 , and 9 , respectively. Tissues were collected 4 hours after the last injection (20 SC sections in each group). Data are expressed as the mean \pm SEM. One-way ANOVA, ${ }^{*} P<0.05$, ${ }^{* *} P<0.01$ versus sham; \#\# $P<0.01$ versus $\mathrm{CCl}$. (C) Western blot showing inhibitory effects of $\mathrm{Fz}-8 / \mathrm{Fc}$ on $\mathrm{CCl}$-induced increased phosphorylation of NR2B, CaMKII, Src, PKC $\gamma$, ERK, and CREB. Fz-8/Fc (4 $\mu$ g, i.t.) was given once a day on postoperative days 7,8 , and 9 , respectively. Tissues were collected 4 hours after the last injection $(n=4$ each group). (D) Data summary of $\mathbf{C}$. One-way ANOVA, ${ }^{\star} P<0.05,{ }^{\star \star} P<0.01$ versus sham; ${ }^{\#} P<0.05,{ }^{\# \#} P<0.01$ versus $\mathrm{CCl}+\mathrm{PBS}$.

rylated active $\beta$-catenin, was significantly increased in a time-related pattern following TCI treatment (Figure 5C). Unlike WNT3a, FZ8, and $\beta$-catenin, the increased expression of FZ1 started at 7 days, approximately 2 days later than that of WNT3a, FZ8, and $\beta$-catenin, and persisted as long as the expression of WNT3a, FZ8, and $\beta$-catenin (Figure 5C). Such a pattern of FZ1 expression after TCI was also different from that observed after CCI, where FZ1 was rapidly onset (within 1 day) and quickly recovered (within approximately 5 days). This suggests the complexity of FZ1 in response to different forms of stressful stimulation.
TCI-induced bone cancer pain in mice, manifested as mechanical allodynia and thermal hyperalgesia, became detectable at 7 days and lasted for at least 21 days, the last day examined, after TCI treatment (Figure 5D). Alterations of WNT3a, FZ8, and $\beta$-catenin expression in the SC occurred approximately 2 days prior to the onset of bone cancer pain and persisted until day 21 (see Figure $5, \mathrm{~A}$ and $\mathrm{C}$ ). These results indicate a correlation between the WNT3a/FZ8/ $\beta$-catenin signaling time-course changes and pain measures, suggesting that TCI-induced rapid-onset and long-lasting upregulation of WNTs and activation of WNT/FZ8/ $\beta$-catenin 


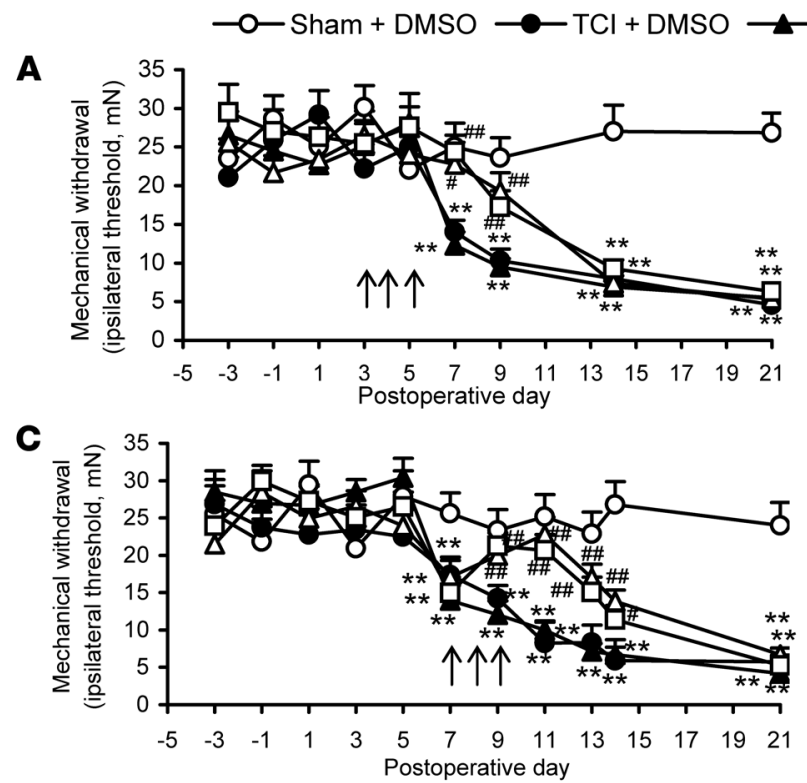

$\mathrm{TCl}+$ human $\mathrm{Fc} \rightarrow-\mathrm{TCl}+\mathrm{IWP}-2-\square-\mathrm{TCl}+\mathrm{Fz}-8 / \mathrm{Fc}$

口Sham + DMSO

\section{E}

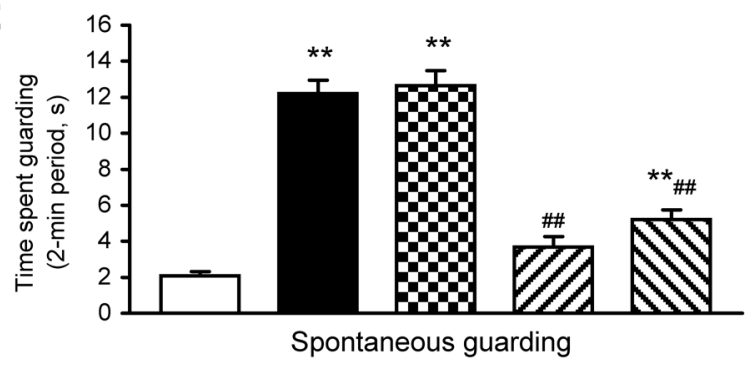

G

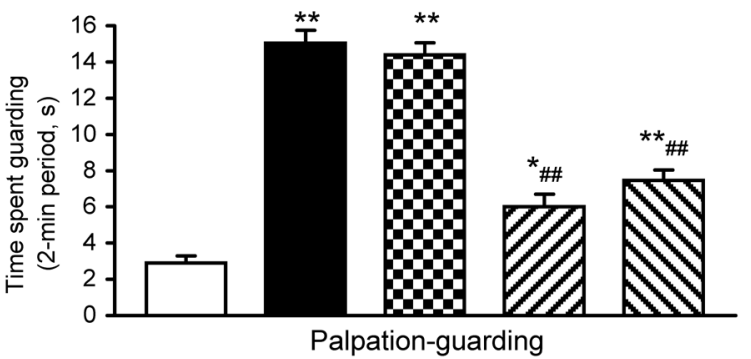

B

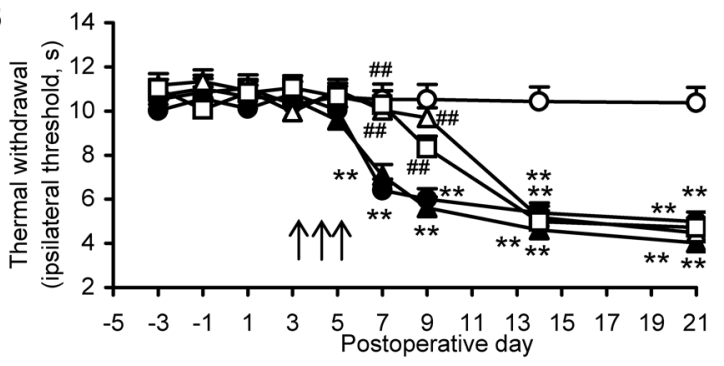

D

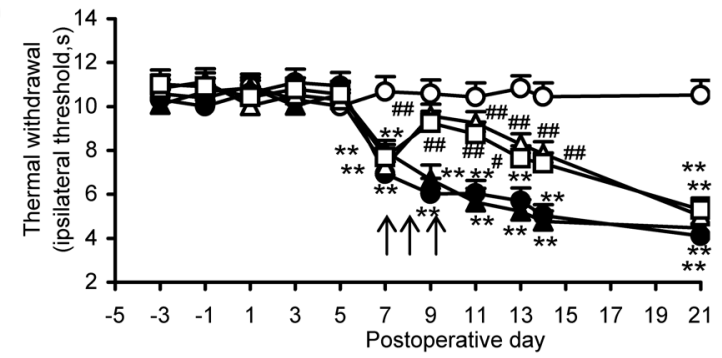

$\mathbf{0} \mathrm{TCl}+$ human FC $\quad \mathbf{D T C l}+\mathrm{IWP}-2 \quad \mathbf{v} \mathrm{TCl}+\mathrm{Fz}-8 / F \mathrm{C}$

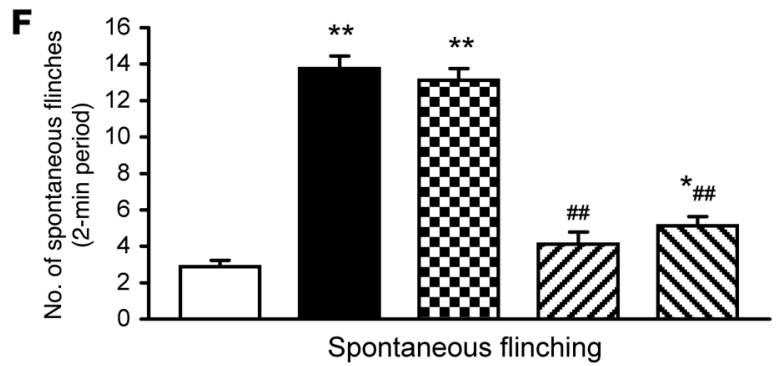

H

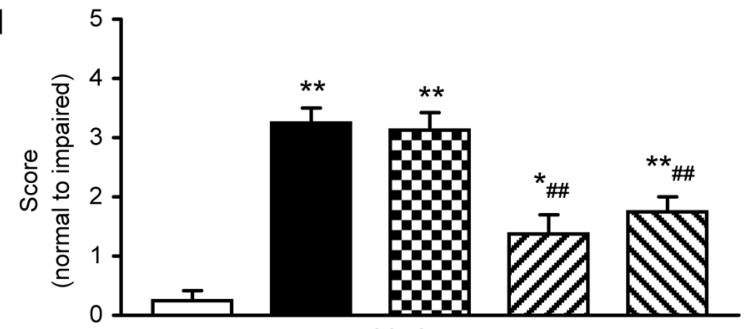

Figure 9

Spinal blockade of WNT signaling inhibits bone cancer pain in TCI mice. (A-D) Blocking WNT signaling in the early phase delayed the onset of mechanical allodynia (A) and thermal hyperalgesia (B), while in the later phase, it suppressed the ongoing mechanical allodynia (C) and thermal hyperalgesia (D). Each administration is indicated by an arrow on the corresponding time point. $(E-H)$ Blocking WNT signaling reduced TCl-induced spontaneous pain manifested as guarding $(\mathbf{E})$ and flinching $(\mathbf{F})$, as well as movement-evoked pain manifested as guarding $(\mathbf{G})$ and reduced limb use $(\mathbf{H})$. Three doses of each drug were given daily for 3 consecutive days on days 7, 8, and 9 after TCl. Drug doses (A-H) (i.t., $10 \mu \mathrm{ll})$ : IWP-2 (10 $\mu \mathrm{M})$; Fz-8/Fc (2 $\mu \mathrm{g})$; human Fc $(2 \mu \mathrm{g})$; and DMSO (1\%). The human Fc and DMSO were used as controls. Measurements were made 4 hours after the last injection. Eight rats were included in each group. Two-way ANOVA (A-D), 1-way ANOVA (E-H). An individual Student's $t$ test was used to test the specific difference between the drug-treated group and its control groups $(\mathbf{A}$ and $\mathbf{B})$, and between the data point before drug administration and each of the data points after drug administration $(\mathbf{C}$ and $\mathbf{D}) .{ }^{*} P<0.05,{ }^{\star \star} P<0.01$ versus sham + DMSO. ${ }^{*} P<0.05,{ }^{\# \#} P<0.01$ versus $\mathrm{TCl}+\mathrm{DMSO}$ and/or $\mathrm{TCl}+$ human $\mathrm{Fc}$.

signaling may contribute to the production and persistence of bone cancer pain. However, FZ1 expression was increased until cancer pain behaviors were detected, suggesting that FZ1 may not contribute to the production of bone cancer pain.

CFA treatment results in a delayed upregulation of WNTs, FZ8, and $\beta$-catenin. Mechanisms underlying NP and IP are different and those underlying bone cancer pain may involve a combination of
NP and IP. Given that the expression of WNTs and WNT/FZ/ $\beta$ catenin signaling was greatly increased after CCI and TCI treatment, respectively, we examined possible changes in WNTs and WNT/FZ/ $\beta$-catenin signaling pathways following CFA-induced acute peripheral inflammation. After CFA injection, the expression of WNT3a in the SC was not significantly altered at the examined points at 2, 6, and 12 hours. The detectable, increased 


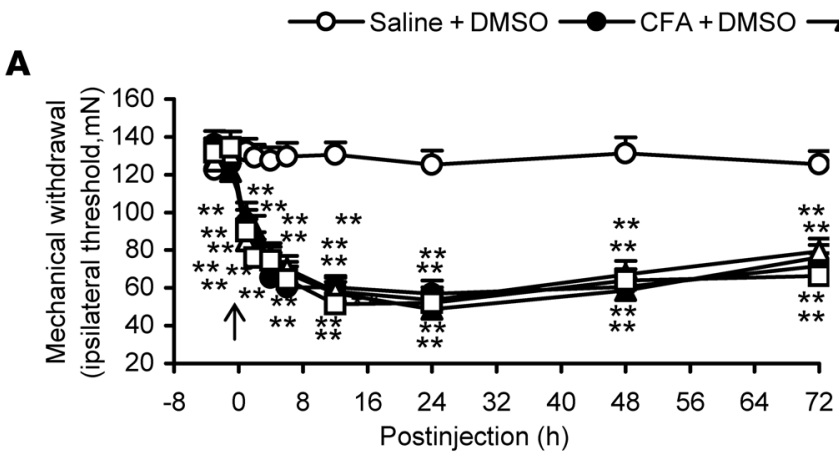

B

C

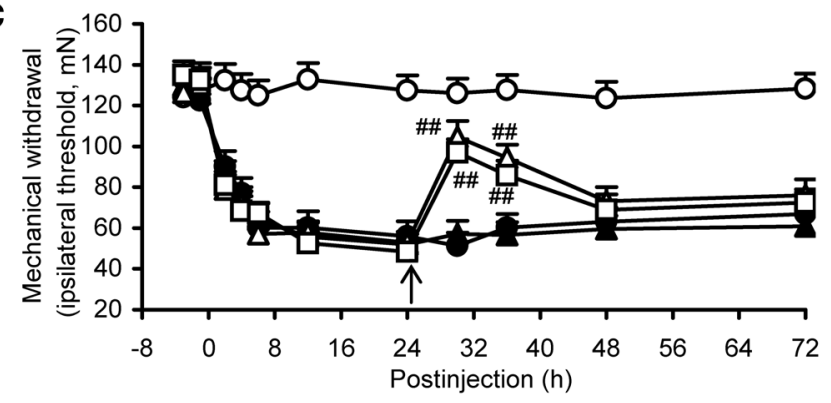

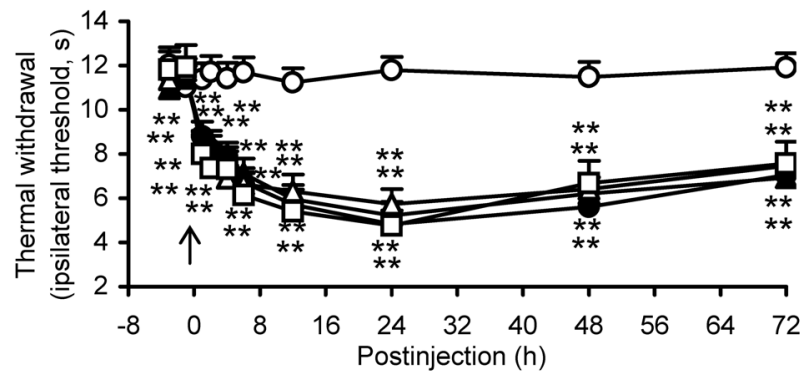

D

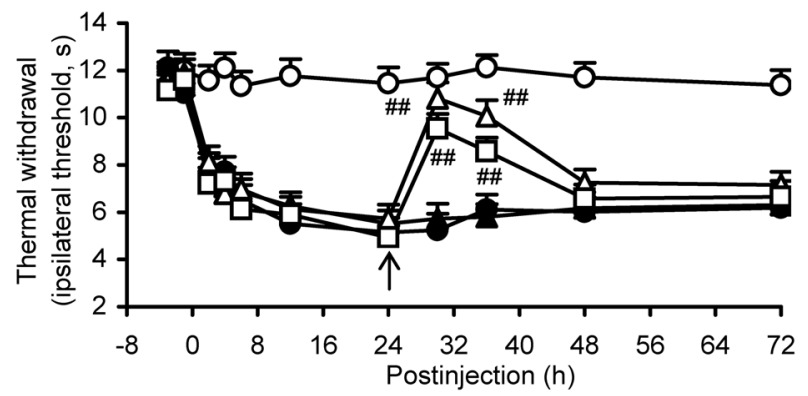

Figure 10

Spinal blockade of WNT signaling transiently inhibits the persistence, but not the production, of CFA-induced inflammatory pain in rats. (A and B) Effects of IWP-2 and Fz-8/Fc on the production of CFA-induced mechanical allodynia (A) and thermal hyperalgesia (B). Each of the drugs was administered 60 minutes before CFA injection. (C and D) Effects of IWP-2 and Fz-8/FC on CFA-induced ongoing mechanical allodynia (C) and thermal hyperalgesia (D). Each of the drugs was given immediately after the 24-hour test following CFA injection. Drug doses (i.t., $20 \mu$ l): IWP-2 (20 $\mu \mathrm{M})$; Fz-8/Fc $(4 \mu \mathrm{g})$; human Fc $(4 \mu \mathrm{g})$; and DMSO (1\%). The human Fc and DMSO were used as controls. Eight rats were included in each group. Two-way ANOVA (A and $\mathbf{B}$ ) and an individual Student's $t$ test (C and $\mathbf{D}$ ) was used to test the specific difference between the drug-treated group and its control groups ( $\mathbf{A}$ and $\mathbf{B})$, and between the data point before drug administration and each of the data points after drug administration $(\mathbf{C}$ and $\mathbf{D})$. ${ }^{* *} P<0.01$ versus saline + DMSO. ${ }^{\# \# P}<0.01$ versus CFA + DMSO, CFA + human Fc, and/or the 24-hour data point before drug administration.

expression of WNT3a started at 24 hours and maintained its high level through 48 and 72 hours (Figure 6A). The increased WNT3a protein immunoreactivity was distributed predominantly in the superficial layers of the DH ipsilateral to the CFA treatment. WNT3a immunoreactivity was greatly colocalized with neuronal somata, dendrites, and astrocytes, but not with microglial cells (Figure 6B). Following CFA injection, expression in the SC of the WNT receptor FZ8, as well as phosphorylated $\beta$-catenin and dephosphorylated active $\beta$-catenin, was significantly increased in a time-related pattern, which was similar to that of WNT3a. In contrast, FZ1 expression was not altered (Figure 6C). Note that CFA-induced expression of WNT3a, FZ8, and $\beta$-catenin occurred approximately 24 hours ( 1 day) after, not prior to, the onset of CFA-induced behaviorally expressed mechanical allodynia, which developed within 1 hour of CFA injection (the first test) and lasted at least 72 hours (Figure 6D). These results suggest that the increased WNT/FZ8/ $\beta$-catenin signaling is the result of, but not the reason for, CFA-induced IP. Thus, WNT signaling does not seem to contribute to the production of IP.

Blocking WNT signaling suppresses the induction and persistence of NP after CCI and TCI, but not the induction of IP after CFA. NP is characterized by behavioral signs of mechanical allodynia and thermal hyperalgesia - neurochemical signs of c-Fos induction - as well as activation of astrocytes and microglial cells and increased expression of the NMDA receptor and subsequent $\mathrm{Ca}^{2+}$-dependent sig- nals in the DH. To determine the role of WNT signaling in NP, we used 5 drugs that inhibit WNT signaling pathways via different mechanisms: (a) IWP-2, a WNT production inhibitor (19); (b) Fz-8/Fc, a WNT scavenger (20); (c) niclosamide (Nsm); and (d) IWR-1-endo (IWR) (both Nsm and IWR were inhibitors of the WNT/FZ/ $\beta$-catenin pathway) (21). With the goal of targeting the WNT signaling pathway in the SC, the drugs were delivered into the spinal fluid by intrathecal (i.t.) administration (in a volume of $20 \mu \mathrm{l}$ in rats and $10 \mu \mathrm{l}$ in mice).

In CCI rats, repetitive administration of each of the following drugs: IWP-2 (20 $\mu \mathrm{M}), \mathrm{Fz}-8 / \mathrm{Fc}(4 \mu \mathrm{g})$, Nsm (1 mM), and IWR $(5 \mu \mathrm{M})$ in the early phase (daily for 3 consecutive days, starting 30 minutes before surgery), significantly delayed production of mechanical allodynia for 2 to 14 days (Figure 7, A and B). The same drugs administrated in the late phase (on postoperative days 7, 8, and 9) produced long-lasting inhibitory effects on the established mechanical allodynia. Such analgesia lasted 4-6 days (IWP-2 and $\mathrm{Fz}-8 / \mathrm{Fc}$ ) or 2-4 days (Nsm and IWR) after termination of the third treatment (Figure 7, C and D). A single treatment of each of these drugs 7 days after CCI produced a transient, significant inhibition of the established mechanical allodynia for 12 to 24 hours (Supplemental Figure 9). Our results showed similar inhibitory effects of these treatments on thermal hyperalgesia after CCI treatment (Supplemental Figure 10). Conversely, i.t. delivery of WNT agonist (20 and $40 \mu \mathrm{M}$ ), an exogenous, selective activator of WNT signal- 
ing, caused rapid-onset (within 2 hours) and long-lasting (greater than 12 hours) mechanical and thermal hypersensitivity in naive rats (Figure 7, E and F). CCI-induced induction of c-Fos and activation of astrocytes and microglial cells were greatly suppressed by repetitive i.t. administration of IWP-2 $(20 \mu \mathrm{M})$ (Figure 8, A and B). CCI-induced activation of the NMDA receptor subtype NR2B and subsequent $\mathrm{Ca}^{2+}$-dependent signals CaMKII, Src/Tyr418, pPKC $\gamma$, ERK, and cAMP response element-binding protein (CREB) $(22,23)$ in the SC was also greatly suppressed by i.t. delivery of $\mathrm{Fz}-8 / \mathrm{FC}(4$ $\mu \mathrm{g})$ (Figure 8, C and D). These results demonstrate that inhibition of WNT production and $\mathrm{WNT} / \beta$-catenin signaling can prevent and suppress the production and persistence of CCI-induced NP, as well as the accompanying neurochemical sign alterations, the $\mathrm{NR} 2 \mathrm{~B}$ receptor, and the subsequent $\mathrm{Ca}^{2+}$-dependent signals within the SC pain pathways. These findings indicate an essential role of WNT signaling in NP development.

Drug doses were chosen based on the specific drug's $\mathrm{EC}_{50}$ or $\mathrm{IC}_{50}$, the limited previous reports (19), and our preliminary experiments (an example is given in Supplemental Figure 11A). Neither of these drugs significantly altered normal pain thresholds (Supplemental Figure 11, B and C) or locomotor activity (Supplemental Figure 12 ) in naive rats, and neither resulted in obvious side effects or animal death.

Mice that received TCI exhibited mechanical allodynia and thermal hyperalgesia (Figure 9, A-D), spontaneous pain manifested as guarding and flinching, as well as movement-evoked pain manifested as palpation guarding and reduced limb use (Figure 9, E-H). The production and persistence of these bone cancer pain-related behaviors were greatly suppressed by daily i.t. administration of IWP-2 $(20 \mu \mathrm{M})$ and $\mathrm{Fz}-8 / \mathrm{Fc}(2 \mu \mathrm{g})$ in the early phase (postoperative days 3, 4, and 5) (Figure 9, A and B) and the later phase (postoperative days 7,8 , and 9 ) (Figure 9, $\mathrm{C}-\mathrm{H}$ ), respectively.

Unlike CCI- or TCI-induced NP, the production of CFA-induced $(100 \mu$ l, s.c.) mechanical allodynia and thermal hyperalgesia in rats was not inhibited by IWP-2 $(20 \mu \mathrm{M})$ and Fz-8/Fc (4 $\mu \mathrm{g})$ (i.t. delivery 60 minutes prior to CFA injection), respectively (Figure 10, A and $\mathrm{B})$. Meanwhile, CFA-induced ongoing pain was reduced by IWP-2 $(20 \mu \mathrm{M})$ and Fz-8/Fc $(4 \mu \mathrm{g})$ (i.t., 24 hours after CFA injection), respectively (Figure 10, C and D). These findings indicate that blocking WNT signaling pathway activation can suppress the production and persistence of NP induced by CCI and TCI, respectively, but not IP induced by CFA.

Activation of WNT/ $\beta$-catenin signaling regulates the production of IL-18 and TNF- $\alpha$. To define the mechanisms by which WNT signaling induces NP, we first examined the activity of the proinflammatory cytokine IL-18 and its receptor IL-18R and the process by which WNT/ $\beta$-catenin activation could regulate these cytokines in the SC. These cytokines are important regulators of innate and acquired immune responses and are essential for the generation of NP (2426). The CCI rat model was used in this study. After CCI, mRNA and protein expression levels of IL-18 and IL-18R in the SC were rapidly (within 1 day) and greatly increased, lasting at least 21 days until final detection (Figure 11, A and B). Repetitive i.t. administration of WNT signaling and WNT/FZ/ $\beta$-catenin pathway inhibitors Fz-8/Fc $(4 \mu \mathrm{g})$, IWR $(5 \mu \mathrm{M})$, and Nsm $(1 \mathrm{mM})$, respectively, significantly inhibited CCI-induced upregulation of IL18 and IL18R, as well as $\beta$-catenin and active $\beta$-catenin (Figure 11C). Conversely, i.t. delivery of exogenous WNT agonist $(40 \mu \mathrm{M})$ caused a rapidly increased (within 2 hours) expression of IL18 and IL18R, as well as $\beta$-catenin and active $\beta$-catenin (Figure 11D). These results indicate that alteration of IL-18 and IL-18R activity in the SC after CCI is regulated by WNT signaling activation, and that WNT signaling can directly regulate IL-18 and its receptor IL-18R.

After WNT ligands bind to FZ receptors, intracellular $\beta$-catenin is stabilized by inactivation of the $\beta$-catenin degradation complex. $\beta$-Catenin is then translocated to the nucleus in order to activate TCF/LEF transcription factors that bind to the WNT target gene promoter regions and to initiate the transcription of WNT-responsive genes $(3,4,27)$. To determine whether the $\beta$-catenin/TCF/LEF complex binds in vivo to the IL-18 promoter, we performed a ChIP assay with specific primer pairs encompassing the TCF-binding site. Our ChIP assay showed that an anti- $\beta$-catenin antibody precipitated chromatin DNA containing IL-18 promoter sequences (Figure 11E). This finding supports the claim that $\beta$-catenin formed a transcriptional complex with TCF/LEF at the IL-18 promoter regions. $\beta$-Catenin and IL-18 overlap in the DH is further shown by confocal images (Figure $11 \mathrm{~F}$ ).

We also examined the activity of proinflammatory cytokines TNF- $\alpha$ and IL- $1 \beta$ and the process by which WNT/ $\beta$-catenin activation could regulate them. CCI significantly increased mRNA and protein expression levels of both TNF- $\alpha$ and IL- $1 \beta$ in the SC (Figure 12, A and B). Repetitive i.t. administration of Fz-8/Fc (4 $\mu$ g), IWR (5 $\mu \mathrm{M})$, and Nsm (1 mM), respectively, significantly inhibited CCI-induced upregulation of TNF- $\alpha$, but not IL-1 $\beta$ (Figure 12C). Conversely, i.t. exogenous WNT agonist $(40 \mu \mathrm{M})$ increased the expression of TNF- $\alpha$, but not IL-1 $\beta$ (Figure 12D). The ChIP assay further showed that an anti- $\beta$-catenin antibody precipitated chromatin DNA containing promoter sequences of TNF- $\alpha$ (Figure 12E), but not those of IL-1 $\beta$ (Figure 12F). These findings support the claim that $\beta$-catenin formed a transcriptional complex with TCF/LEF at TNF- $\alpha$, but not at IL- $1 \beta$, promoter regions.

Furthermore, spinal blockade of IL-18 and IL-18R with IL-18binding protein (IL-18BP, i.t., $1 \mu \mathrm{g}$ ) and IL-18R antibody (antiIL-18R, $2 \mu \mathrm{g}$ ), respectively, significantly suppressed CCI- and WNT agonist-induced mechanical and thermal hypersensitivity (Figure 13). Taken together, these findings strongly support the idea that activation of WNT/ $\beta$-catenin signaling may induce NP through regulating proinflammatory cytokines, including IL-18 and TNF- $\alpha$.

\section{Discussion}

Our study reveals a critical role for WNT signaling in the production and persistence of NP after nerve injury and bone cancer. NP-inducing nerve injury and bone cancer, respectively, activate WNT signaling, which may contribute to NP by regulating proinflammatory cytokines IL-18 and TNF- $\alpha$, as well as NR2B and subsequent $\mathrm{Ca}^{2+}$-dependent signals in the DH. The principle findings are 4-fold: (a) Nerve injury (CCI treatment) and bone cancer (TCI treatment), respectively, cause rapid-onset and long-lasting activation of the WNT/FZ8/ $\beta$-catenin signaling pathway in $\mathrm{DH}$ neurons and astrocytes. However, in DRG neurons, WNTs may function through FZ8 nuclear transport and/or other $\beta$-catenin-independent pathways. CFA treatment-induced inflammation results in delayed activation of the WNT3a/FZ8/ $\beta$-catenin pathway, which occurs after the onset of behaviorally expressed pain. (b) Spinal blockade of WNT signaling pathways inhibits the production and persistence of CCI-induced NP and TCI-induced bone cancer pain without affecting normal pain sensitivity or locomotor activity. Thus, WNT3a/FZ8/ $\beta$-catenin signaling activation may contribute to the development and maintenance of CCI- and TCI-induced NP. In contrast, spinal blockade of 


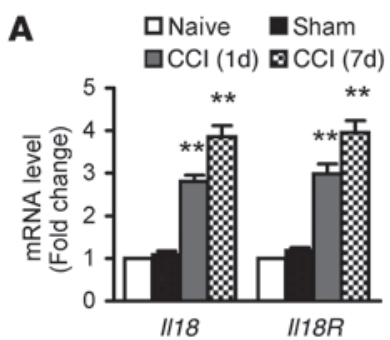

C
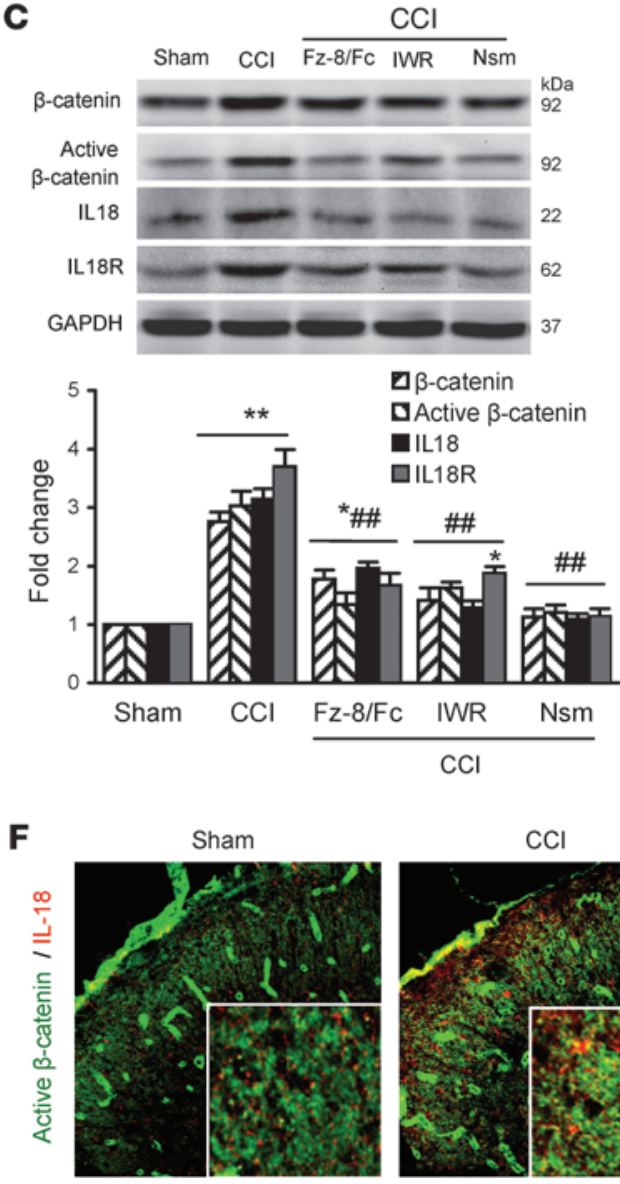

B

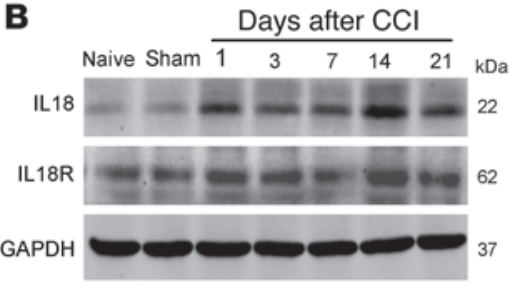

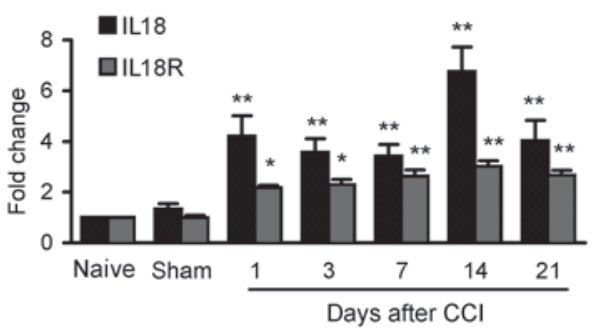

Days after $\mathrm{CCl}$
D
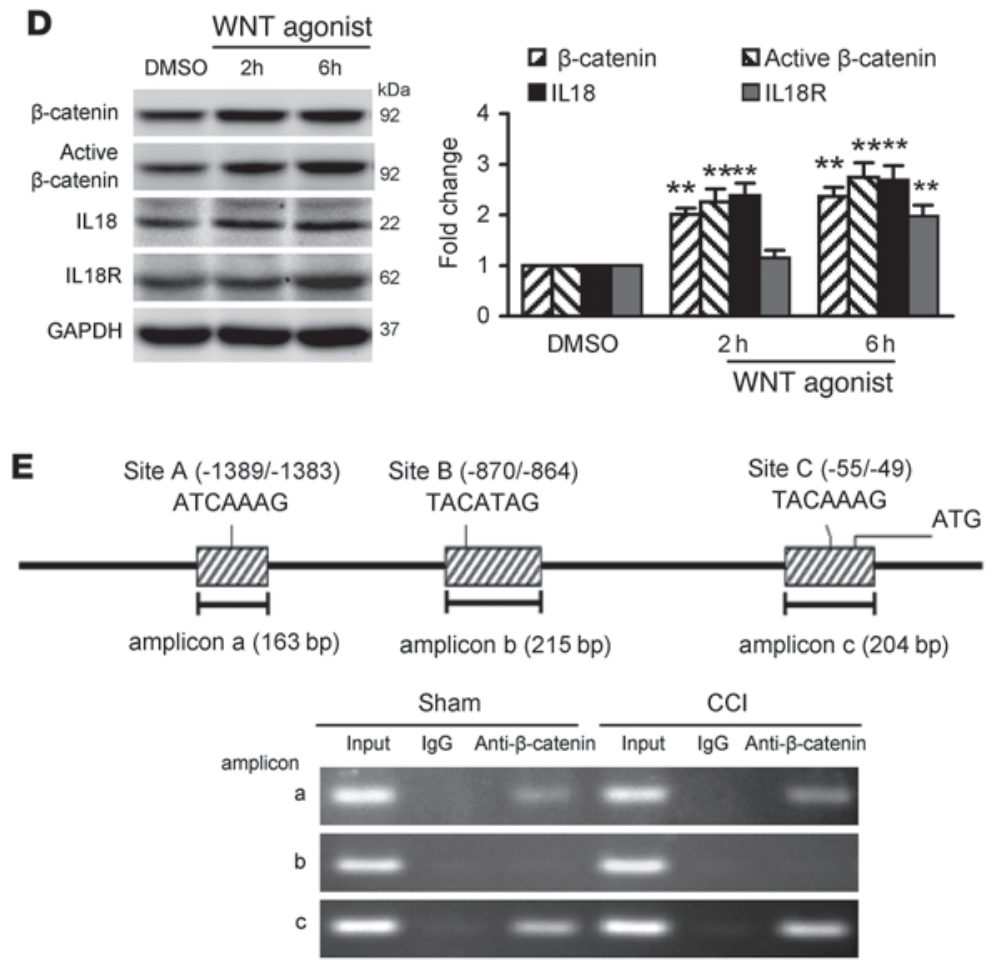

Figure 11

Activation of the WNT/ $\beta$-catenin pathway mediates production of IL-18 in rat SC after CCI. (A) qRT-PCR showing increased mRNA levels of II18 and II18R at 1 ( $\mathrm{CCl} 1 \mathrm{~d})$ and $7(\mathrm{CCl} 7$ d) days after $\mathrm{CCl}(n=3)$. (B) Western blot showing time courses for the expression of IL18 and IL18R $(n=4)$. (C) Administration of WNT/ $\beta$-catenin inhibitors suppresses CCI-induced upregulation of $\beta$-catenin, active $\beta$-catenin, IL 18, and IL18R. Each of the drugs ( $\mathrm{Fz}-8 / \mathrm{Fc}, 4 \mu \mathrm{g}$; IWR, $5 \mu \mathrm{M}$, and Nsm, $1 \mathrm{mM}$ ) were given (i.t., in a volume of $20 \mu \mathrm{l}$ ) daily on postoperative days 5,6 , and 7 , respectively. Tissues were collected 4 hours after the last drug administration $(n=4)$. (D) WNT agonist $(40 \mu \mathrm{M}, 20 \mu$ l, i.t.) activates $\beta$-catenin, IL-18 and IL-18R $(n=4)$. One-way ANOVA (A-D) with an individual Student's $t$-test $(\mathbf{C}) .{ }^{*} P<0.05,{ }^{\star \star} P<0.01$ versus naive and sham $(\mathbf{A}-\mathbf{C})$ or DMSO $(1 \%)(\mathbf{D})$. ${ }_{\# \# P<0.01 \text { versus } C C I}(\mathbf{C})$. (E) ChIP-PCR assay showing that an anti- $\beta$-catenin antibody precipitated chromatin DNA containing a promoter sequence of the I/18 gene. Schematic representation of 3 potential TCF-binding sites in the I/18 promoter region (top). PCR analyses of DNA pulled down by IgG (negative control) or anti- $\beta$-catenin (bottom). Input samples were used as a positive control. (F) Confocal images show overlapping of $\beta$-catenin and IL-18 in the $\mathrm{DH}(7$ days after $\mathrm{CCl})$.

WNT signaling does not alter the production of CFA-induced IP, although CFA-induced ongoing pain is transiently suppressed. Thus, WNT3a/FZ8/ $\beta$-catenin signaling activation does not contribute to the development of CFA-induced IP, though it may facilitate the ongoing pain. (c) Spinal blockade of WNT signaling pathways inhibits CCI-induced induction of c-Fos and acti- vation of astrocytes and microglial cells, as well as activation of NR2B and the subsequent $\mathrm{Ca}^{2+}$-dependent signals in the DH. This further confirms the importance, after nerve injury, of WNT3a/ $\mathrm{FZ8} / \beta$-catenin signaling in signal transduction and synaptic plasticity alterations, which are essential to SC central sensitization. (d) WNT signaling activation in the SC may contribute to NP 
A

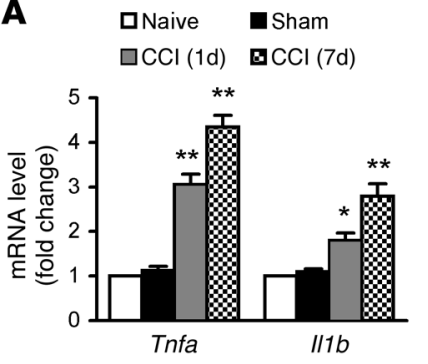

B

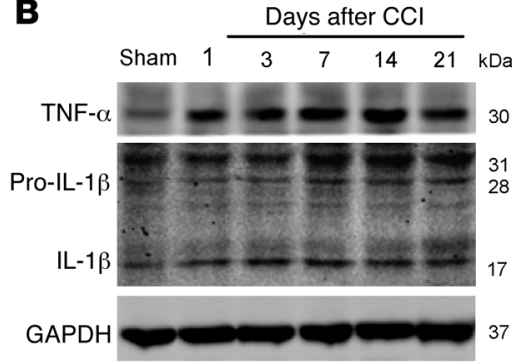

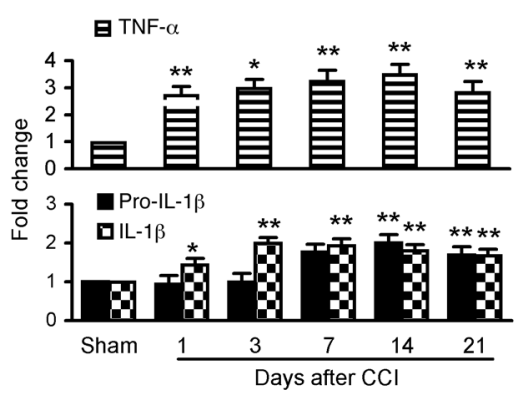

D

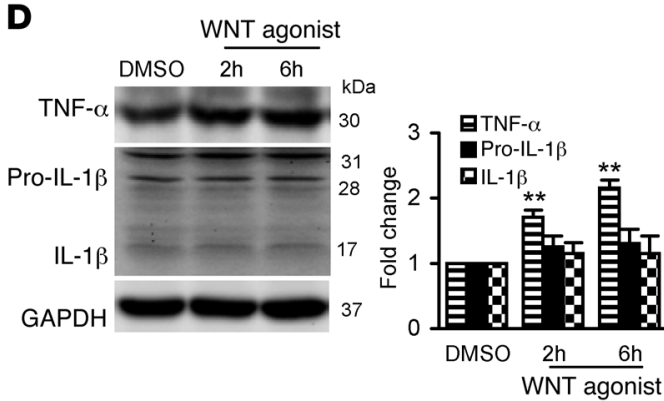

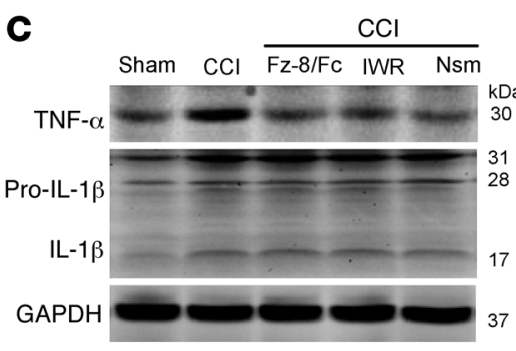

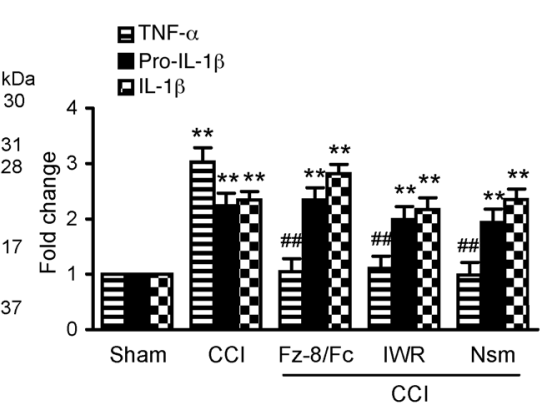

$\mathbf{E}$

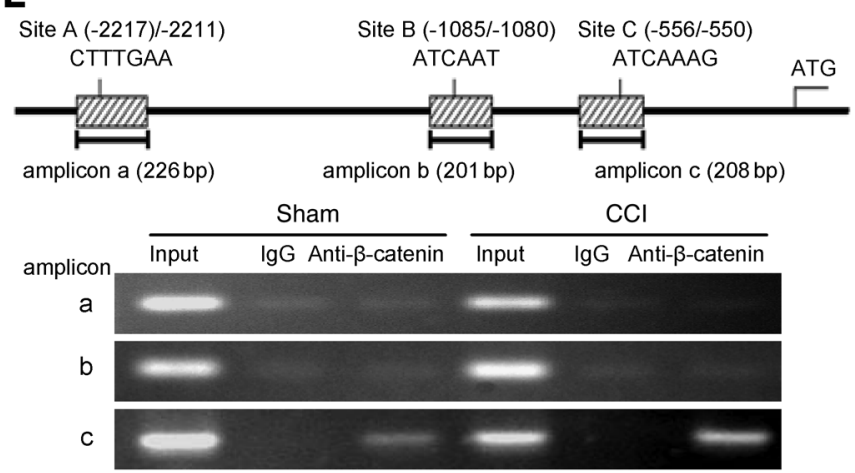

$\mathbf{F}$

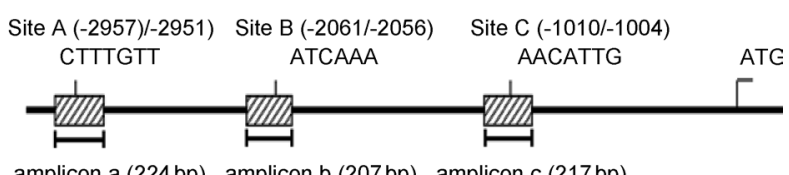

amplicon a (224bp) amplicon b (207bp) amplicon c (217bp)

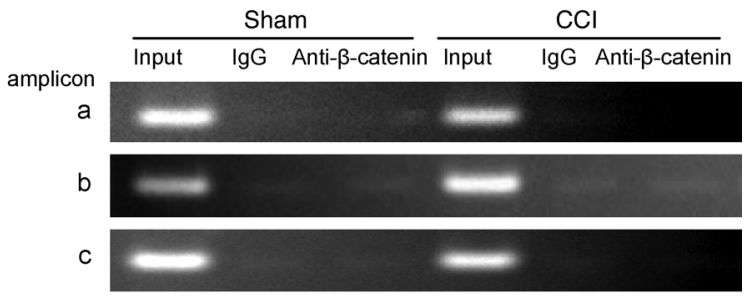

Figure 12

WNT/ $\beta$-catenin signal activation mediates the production of TNF- $\alpha$, but not IL-1 $\beta$, in rat SC after CCI. (A) qRT-PCR showing increased mRNA levels of Tnfa and II1 b at $1(\mathrm{CCl} 1 \mathrm{~d})$ and 7 ( $\mathrm{CCl} 7 \mathrm{~d})$ days after $\mathrm{CCl}(n=3)$. (B) Western blot showing time courses for the expression of TNF- $\alpha$ and IL-1 $\beta(n=3)$. (C) Blocking the WNT/ $\beta$-catenin pathway suppresses CCl-induced upregulation of TNF- $\alpha$, but not IL-1 $\beta$. Each of the drugs (Fz-8/Fc, $4 \mu \mathrm{g}$; IWR, $5 \mu \mathrm{M}$; and Nsm, $1 \mathrm{mM}$ ) was given (i.t., in a volume of $20 \mu \mathrm{l}$ ) daily on postoperative days 5, 6, and 7. Tissues were collected 4 hours after the last i.t. administration $(n=4)$. (D) WNT agonist $(40 \mu \mathrm{M}$, i.t.) activates TNF- $\alpha$, but not IL-1 $\beta(n=4)$. GAPDH in $\mathbf{C}$ and $\mathbf{D}$ was from the same samples in Figure 11, C and D. One-way ANOVA (A-D) with an individual Student's $t$ test $(\mathbf{C})$. ${ }^{*} P<0.05,{ }^{* *} P<0.01$ versus naive and sham $(\mathbf{A}-\mathbf{C})$ or DMSO (1\%) (D). \#\# $P<0.01$ versus $\mathrm{CCl}(\mathbf{C})$. (E and $\mathbf{F})$ ChIP-PCR assay showing that an anti- $\beta$-catenin antibody precipitated chromatin DNA containing a Tnfa $(\mathbf{E})$, but not an $/ 11 b(\mathbf{F})$ promoter sequence gene. Schematic representation of 3 potential TCF-binding sites in the promoter region of $\operatorname{Tnfa}(\mathbf{E})$ and $/ 11 \mathrm{~b}(\mathrm{~F})$ (top). PCR analyses of DNA pulled down by IgG (negative control) or anti- $\beta$-catenin (bottom). Input samples were used as a positive control.

production and persistence by stimulating production of proinflammatory cytokines IL-18 and TNF- $\alpha$ through the $\beta$-catenin pathway. We believe that these findings may support a new mechanism underlying NP and a new therapeutic opportunity for its treatment after nerve injury and bone cancer.

WNTs are known to be important for various developmental processes. Studies have demonstrated the dysregulation of WNT signaling in certain diseases and disorders, e.g., WNT signaling is upregulated in schizophrenic brains (28) and downregulated in brains with Alzheimer disease $(29,30)$. Expression of many WNT signal-related genes can be altered following cocaine exposure (31) or SC contusion injury (32). Here, we show that peripheral nerve injury and bone cancer can cause dramatic and time-dependent changes in the physiological pattern of mRNA and/or protein expression of WNTs and WNT-binding receptors. The early and later induction of WNT and WNT-binding Fz receptor genes suggest that each of the specific subtypes may function at different stages after nerve injury. WNT3a is a well-characterized activator of $\beta$-catenin-dependent canonical and noncanonical pathways and is broadly studied in the development and regeneration of nervous systems $(2,3,5,11,12)$. Our results indicate a rapid-onset and long-lasting increased expression of WNT3a in DRG and/or 

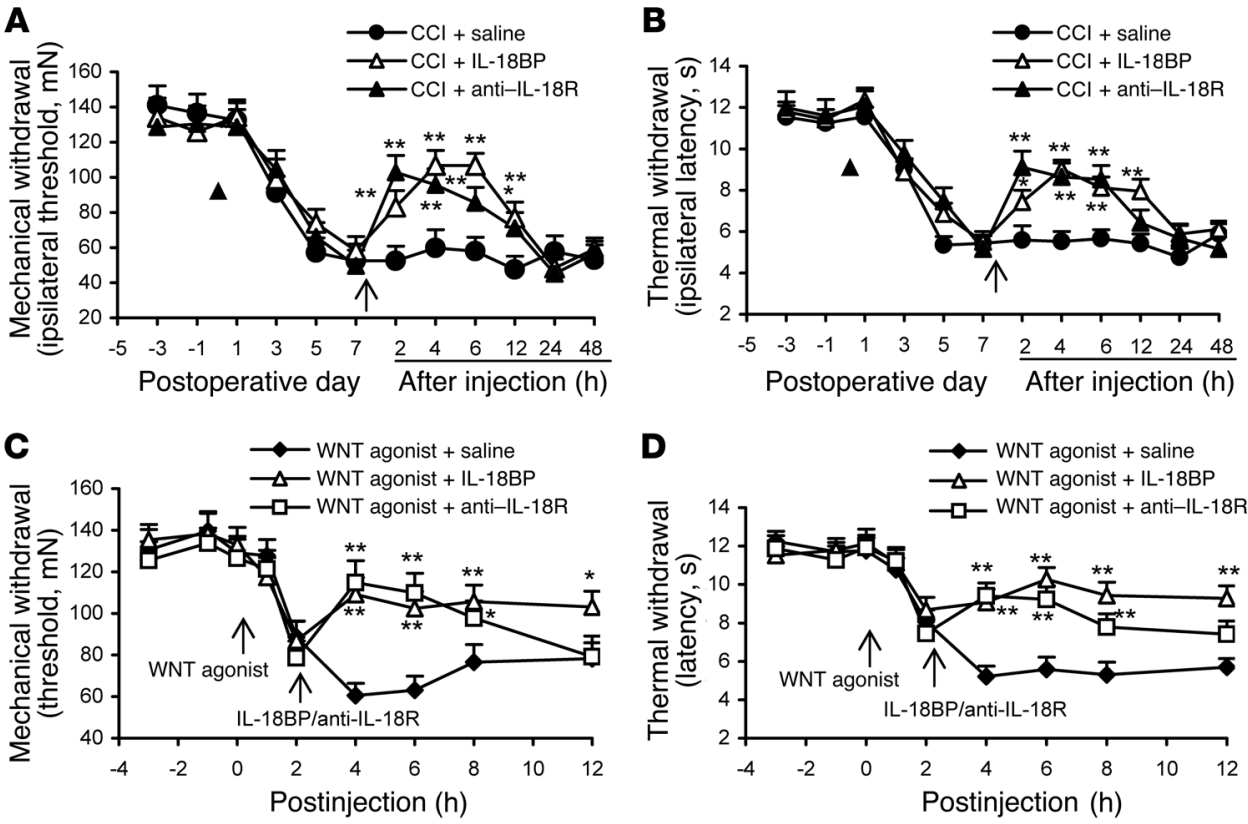

\section{Figure 13}

Spinal blockade of IL-18 and IL-18R reverses mechanical and thermal hypersensitivity induced by CCI and i.t. WNT agonist, respectively, in rats. (A and B) CCl-induced mechanical allodynia (A) and thermal hyperalgesia (B). (C and D) WNT agonist-induced mechanical allodynia (C) and thermal hyperalgesia (D). Drug doses (i.t., in a volume of $20 \mu \mathrm{l})$ : IL-18 antagonist IL-18BP (1 $\mu \mathrm{g})$; IL-18R antibody (anti-IL-18R, $1 \mu \mathrm{g}$ ); and WNT agonist $(40 \mu \mathrm{M})$. Arrows indicate the drug administrations. Eight rats were included in each group. (A-D) Two-way ANOVA with an individual Student's $t$ test were used. ${ }^{*} P<0.05,{ }^{* \star} P<0.01$ versus WNT agonist + saline, respectively. Black triangles indicate $\mathrm{CCl}$ surgery $(\mathbf{A}$ and $\mathbf{B})$.

the DH after nerve injury and bone cancer. The greatly increased expression of WNT3a occurs prior to the onset of behaviorally expressed pain after nerve injury and bone cancer, respectively, and persists with the ongoing pain behaviors. Spinal blockade of WNT signaling can inhibit the production and persistence of CCI-induced NP and TCI-induced bone cancer pain, the accompanying induction of c-Fos and activation of astrocytes and microglial cells, as well as the activation of NR2B and the subsequent $\mathrm{Ca}^{2+}$-dependent signals. These findings support the idea that WNTs, such as WNT3a, may be among the important proteins that are activated by nerve injury and other forms of stress such as bone cancer, and are thus involved in pain development. However, in the CFA-induced IP model, a significantly delayed upregulation of WNT3a (at 24 hours after CFA treatment versus 6 hours after CCI) occurs after, but not prior to, the onset of behaviorally expressed pain (within 2 hours after CFA treatment). Spinal blockade of WNT signaling does not alter the induction of CFA-induced IP. From the findings in these 3 models - CCI, TCI, and CFA - we conclude that WNT signaling plays a specific and essential role in pain production and persistence after nerve injury and bone cancer. The delayed activation of WNT signaling following CFA injection is secondary to the persistent IP and is not a reason for CFA-induced pain production, but such delayed WNT signaling activation does facilitate the ongoing IP.

Binding of the released WNTs to their receptors can activate different intracellular signaling pathways. WNT ligands bind to the cysteine-rich domain $\mathrm{FZ}$ receptors and activate the canonical $\mathrm{WNT} / \beta$-catenin pathway $(33,34)$. $\beta$-Catenin is a multifunctional protein that interacts with transcription factors to activate target gene transcription. Among the nerve injury-induced induction and expression of the $\mathrm{FZ}$ receptor genes and proteins in the $\mathrm{DH}$ neurons, both FZ1 and FZ8 receptors were activated in the early phase (1-5 days). However, in the late phase (7-21 days), only FZ8 was substantially and persistently activated in both neurons and astrocytes. Meanwhile, active $\beta$-catenin was rapidly and persistently increased in both cellular plasma and nuclei (nuclear transport). These findings support the idea that activation of both FZ1 and FZ8 may contribute to WNT-mediated production of NP, while only FZ8 contributes to WNT-mediated persistence of NP. Interestingly, in DRG neurons, CCI causes substantial upregulation of FZ8 expression and FZ8 nuclear transport mostly in small and medium-sized neurons, particularly CGRP-positive neurons, without altering FZ1 and $\beta$-catenin expression. These findings suggest that, in the presynaptic DRG neurons, WNTs may function through FZ8 nuclear transport (35) and/or other $\beta$-catenin-independent pathways after nerve injury. How WNTs and FZ8 nuclear transport in DRG contribute to the development of NP needs to be further investigated. In addition, FZ1 expression exhibits different patterns following CCI, TCI, and CFA treatment in DRG and SC. FZ1 in SC may contribute to the production of NP in a CCI model, but not to the development of pain in TCI and CFA models.

Activation of WNT/ $\beta$-catenin signaling in postsynaptic neurons causes cytoplasmic $\beta$-catenin accumulation. Such accumulated $\beta$-catenin is eventually imported into the nucleus, where it serves as a transcriptional coactivator of TCF/LEF family transcription factors $(3,4,18)$. In this study, we show that both nerve injury and bone cancer stimulation may cause rapid-onset and long-lasting activation of WNT/ $\beta$-catenin signaling pathways in $\mathrm{DH}$ neurons. This upstream activation of $\beta$-catenin is triggered 
by CCI-activated WNTs and WNT-binding FZ receptors, while downstream WNT/ $\beta$-catenin activation regulates the activity of proinflammatory cytokines IL-18 and TNF- $\alpha$, which may directly contribute to the production and persistence of pain. Our ChIP assay confirms that an anti- $\beta$-catenin antibody precipitates chromatin DNA that contains promoter sequences of IL-18 and TNF- $\alpha$, indicating that $\beta$-catenin forms a transcriptional complex with TCF/LEF at the IL-18 and TNF- $\alpha$ promoter regions. However, WNT/ $\beta$-catenin activation does not regulate IL-1 $\beta$ activity, an important proinflammatory cytokine. Expression of IL-18 and TNF- $\alpha$ in the SC is greatly increased by CCI treatment and by spinal administration of an exogenous WNT agonist. In contrast, IL-1 $\beta$ expression is not altered by the exogenous WNT agonist, though it is increased by CCI. The ChIP assay failed to find a $\beta$-catenin transcriptional complex with TCF/LEF at the IL- $1 \beta$ promoter region. These proinflammatory cytokines play an important role in the generation of NP and are known to be upregulated after nerve injury. They also play an important role in several human autoimmune and inflammatory diseases. Thus, blocking WNT/ $\beta$-catenin signaling may provide a strategy for treating NP through IL-18 and TNF- $\alpha$ inhibition.

Clinical approaches to treating NP, including intractable cancer pain, are very limited, and the specific cellular and molecular mechanisms underlying NP remain elusive. Our findings support the idea that NP-inducing nerve injury and other forms of severe stress such as bone cancer may elicit neuronal alterations that recapitulate events that occur during development. These activated molecules, which are important in axon guidance, synaptic connection, and plasticity during development, become triggers for the development of NP and the neurochemical alterations that accompany it, and are thus potential therapeutic targets for treating NP. Indeed, blocking WNT production and WNT signaling pathways at the spinal level greatly suppresses nerve injury-induced behavioral and neurochemical signs of NP and bone cancer pain. This hypothesis is supported by recent reports that WNT signaling is activated by some forms of stress such as cancer development (36) and SC contusion injury (32). In addition to WNT signaling, we have recently demonstrated that ephrinB-EphB receptor signaling - another important signaling system in various processes including tissue border formation, cell migration, axon guidance, synaptic connection, and plasticity during the development of the nervous system - is activated following different forms of severe stress including peripheral nerve injury (37-39), bone cancer (22), and withdrawal of chronic morphine treatment $(22,39,40)$, and contributes to pain and/ or pain enhancement resulting from severe stresses. WNT and ephrinB-EphB signaling interact with each other during the development of the nervous system $(10,41-46)$ and certain cancers $(47,48)$. The contribution to NP of nerve injury-induced activation of these molecules, which play essential roles during the development of nervous systems, is, we believe, a unique and fundamentally different concept from the numerous hypotheses that focus on alterations and phenotypic switches of the nociceptive transmitters and/or modulators that have already exerted their effects on the pain process in mature nervous systems. We believe our findings may open a new avenue to understanding the cellular and molecular mechanisms of NP, and to exploring new approaches for preventing, minimizing, or completely relieving $\mathrm{NP}$ and other forms of severe injury and stress-induced intractable pain such as bone cancer pain.

\section{Methods}

Animals, anesthesia, drugs, and drug administration. We purchased adult male Sprague-Dawley rats (200-220 g body wt) from Charles River Laboratories and mice $(\mathrm{C} 3 \mathrm{H} / \mathrm{HeJ}, 20-25 \mathrm{~g}$ body $\mathrm{wt})$ from The Jackson Laboratory. All surgeries were performed under anesthesia with sodium pentobarbital $(50 \mathrm{mg} / \mathrm{kg}$, i.p.). We purchased IWP-2, IWR, and WNT agonist from EMD Chemicals; Nsm and DMSO from Sigma-Aldrich; Fz-8/Fc and control IgG from R\&D Systems; and human Fc from The Jackson Laboratory. The drug doses were selected on the basis of previous reports and our preliminary experiments. The drugs were delivered i.t. (in a volume of $20 \mu \mathrm{l}$ in rats and $10 \mu \mathrm{l}$ in mice) into cerebral spinal fluid through lumbar puncture.

CCI. We used a rat model of CCI in this study to produce peripheral nerve injury. The left common sciatic nerve of each rat was exposed at the mid-thigh level. The area proximal to the sciatic nerve's trifurcation was freed of adhering tissue, and 4 ligatures (4-0 surgical catgut) were tied loosely around it with approximately $1 \mathrm{~mm}$ between ligatures. Animals in the sham group received surgery identical to that described in CCI, but without nerve injury.

TCI. To produce bone cancer and bone cancer pain, a mouse model of TCI was used. Experiments were performed on adult male $\mathrm{C} 3 \mathrm{H} / \mathrm{HeJ}$ mice. The protocol of tumor cell injection was similar to that described previously $(14,15)$. In brief, under anesthesia, a 0.5 -cm rostrocaudal incision was made in the skin overlying the top half of the tibia after disinfection with $75 \% \mathrm{v} / \mathrm{v}$ ethanol. Tumor cells $\left(2 \times 10^{5}\right.$; NCTC 2472 ; ATCC) in $5 \mu \mathrm{l}$ of $\alpha \mathrm{MEM}$ or $5 \mu \mathrm{l} \alpha \mathrm{MEM}$ alone (sham) were injected into the intramedullary space of the right tibia. The injection site was closed using bone wax while the syringe was removed. The wound was dusted with penicillin powder and then closed.

Assessment of mechanical allodynia and thermal hyperalgesia. Mechanical allodynia was determined by measuring the incidence of foot withdrawal in response to mechanical indentation of the plantar surface of each hindpaw using a sharp, cylindrical probe with a uniform tip diameter of approximately 0.2 mm (ALMEMO 2390-5 Electronic von Frey Anesthesiometer; IITC Life Science). The probe was applied to 6 designated loci distributed over the plantar surface of the foot. The minimal force (in grams) that induced paw withdrawal was read off the display. The threshold of mechanical withdrawal in each animal was calculated by averaging the 6 readings, and the force was converted into millinewtons $(\mathrm{mN})$. Thermal hyperalgesia was assessed by measuring foot withdrawal latency to heat stimulation. An analgesia meter (IITC Model 336 Analgesia Meter, Series 8; IITC Life Science) was used to provide a heat source. In brief, each animal was placed in a box containing a smooth, temperature-controlled glass floor. The heat source was focused on a portion of the hindpaw, which was flush against the glass, and a radiant thermal stimulus was delivered to that site. The stimulus shut off when the hindpaw moved (or after 20 seconds to prevent tissue damage). The intensity of the heat stimulus was maintained constant throughout all experiments. The elicited paw movement occurred at latency between 9 and 14 seconds in the control animals. Thermal stimuli were delivered 3 times to each hindpaw at 5- to 6-minute intervals. For the results expressing mechanical allodynia or thermal hyperalgesia, the values are the mean of the ipsilateral feet. For the results expressing i.t. WNT agonist-induced thermal and mechanical hypersensitivity, the values represent the mean of both feet of the rat. The protocols used for determining the pain-related behaviors are similar to those we have previously described $(38,49,50)$.

Assessment of spontaneous and movement-evoked pain-like behaviors. Bone cancer pain in TCI mice was evaluated by measuring the spontaneous and movement-evoked pain-like behaviors, in addition to the mechanical allodynia and thermal hyperalgesia described in the last paragraph. Spontaneous nocifensive behaviors were evaluated by measuring spontaneous 
guarding and flinching over a 2-minute period of observation. Movement-evoked pain was assessed by measuring the time spent guarding over a 2-minute observation period after non-noxious palpation and limb use during spontaneous ambulation, which was scored on a scale of 0 to 4: $0=$ normal use; 1 = slightly limping; 2 = clearly limping; 3 = no use of the limbs (partial); and $4=$ no use of the limbs. The protocols were similar to those described previously $(22,51,52)$.

Treadmill test. An Exer-6M Treadmill (Columbus Instruments) was used. The protocols were similar to those described previously (53). Rats were placed on a moving belt ( 20 meters per minute with a slope of 10 degrees) facing away from the electrified grid and were induced to run in the direction opposite to the movement of the belt. Thus, to avoid foot shocks with weak electrostimulation $(1.0 \mathrm{~mA})$, the rats had to move forward. The total running time and number of shocks the rats received were recorded. To measure the maximum running speed, the belt speed was steadily increased from 20 meters per minute by 1 meter per minute every 10 seconds.

RT-PCR and quantitative RT-PCR. Under deep anesthesia, the $\mathrm{L}_{4}-\mathrm{L}_{5} \mathrm{SC}$ segments of rats were quickly removed and analyzed. Total RNA was isolated with TRIzol reagent (Invitrogen) according to the manufacturer's instructions. cDNA was then synthesized using a Thermo Scientific Verso cDNA synthesis kit (ABgene, Thermo Scientific) with oligo(dT)18 primer. Expression of the $19 \mathrm{Wnt}$ genes was analyzed by PCR. The standard conditions were: $95^{\circ} \mathrm{C}$ for 5 minutes and then 30 cycles at $95^{\circ} \mathrm{C}$ for 30 seconds, $59^{\circ} \mathrm{C}$ for 30 seconds, and $72^{\circ} \mathrm{C}$ for 60 seconds, and a final extension at $72^{\circ} \mathrm{C}$ for 5 minutes. The extension cycles were changed to 35 cycles for $W n t 1$ and $W n t 9 b$. The primers used for expression analysis of WNT ligands are listed in Supplemental Table 1. Quantitative RT-PCR (qRT-PCR) was performed with a DyNAmo Flash SYBR Green qPCR kit (Thermo Scientific). The thermal cycle conditions used to assess the expression of WNT ligands (Wnt1, Wnt2b, Wnt3a, Wnt5b, Wnt8a, and Wnt8b) were: $95^{\circ} \mathrm{C}$ for 7 minutes; 50 cycles of $95^{\circ} \mathrm{C}$ for 15 seconds, and $59^{\circ} \mathrm{C}$ for 60 seconds, with the primers listed in Supplemental Table 1. The thermal cycle conditions used for detection of the $\mathrm{Fz}$ and cytokine genes were: $95^{\circ} \mathrm{C}$ for 7 minutes; 45 cycles of $95^{\circ} \mathrm{C}$ for 10 seconds, and $58^{\circ} \mathrm{C}$ for 45 seconds. The specific primers used for sequence detection are shown in Supplemental Table 2. Relative mRNA levels were calculated using the $2-\Delta \Delta C T$ method. Gene expression was first normalized to the housekeeping control gene Gadph, and subsequently, the relative expression of genes of interest was compared with the respective experimental control.

Protein determinations. To quantify temporal changes in protein levels of the Wnts and other signals, Western blot analysis was used. The $\mathrm{L}_{4}-\mathrm{L}_{5} \mathrm{DRG}$ and/or SC segments were quickly removed from deeply anesthetized rats and stored at $-80^{\circ} \mathrm{C}$. Sequential precipitation procedures were used on the tissue samples that were lysed in ice-cold $\left(4^{\circ} \mathrm{C}\right) \mathrm{NP}-40$ or RIPA lysis buffer containing a cocktail of protease inhibitor, phosphatase inhibitors, and phenylmethylsulfonyl fluoride (Sigma-Aldrich). For the analyses of nuclear $\beta$-catenin, nuclear extracts were prepared using an NE-PER Nuclear and Cytoplasmic Extraction Kit (Pierce Biotechnology) according to the manufacturer's instructions. Protein concentrations of the lysates were estimated using the bicinchoninic acid (BCA) method (with reagents from Pierce Biotechnology), and the total protein content between samples was equalized. Total proteins were separated by SDS-PAGE and transferred to $0.2 \mu \mathrm{m}$ nitrocellulose or PVDF membrane (both from Bio-Rad). The following primary antibodies were used: anti-Wnt3a (1:1,000; Millipore), anti-Fz-1 (1:400; Abgent), anti-Fz-8 (1:1,000; Bioworld Technology), anti- $\beta$-catenin (1:1,000; BD Biosciences), anti-active $\beta$-catenin (clone 8E7) (1:1,000; Millipore), anti-Histone H3 (1:1,000; Abcam), anti-IL-18 $(2 \mu \mathrm{g} / \mathrm{ml}$; Abnova), anti-IL-18R (1:500; Santa Cruz Biotechnology), anti-TNF- $\alpha$ (1:1,000; Millipore), anti-IL-1 $\beta$ (1:500; Santa Cruz Biotechnology), antipNR2B (Tyr $\left.{ }^{1472}\right)$ (1:300; Millipore), anti-pSrc (pY $\left.{ }^{418}\right)$ (1:1,000; Biosource),
anti-pCaMKII (Thr $\left.{ }^{286}, 3361\right)$ (1:1,000; Cell Signaling Technology), and anti-GAPDH (1:5,000 to 1:35,000; Sigma-Aldrich). The membranes were then developed by enhanced chemiluminescence reagents (PerkinElmer) with horseradish peroxidase-conjugated secondary antibodies (R\&D Systems). Data were analyzed using the Molecular Imager (ChemiDoc XRS; Bio-Rad) and the associated software Quantity One 4.6.5 (Bio-Rad).

Immunohistochemistry. Deeply anesthetized rats were perfused transcardially with $0.9 \%$ saline followed by $4 \%$ formaldehyde. The $\mathrm{L}_{4}-\mathrm{L}_{5} \mathrm{SC}$ segments and DRG were removed and post-fixed in $4 \%$ formaldehyde overnight. Sections $(40-\mu \mathrm{m})$ were cut using the Vibratome 1000 Plus (Vibratome). For immunofluorescence staining, free-floating sections were blocked in TBS containing $5 \%$ donkey serum or $5 \%$ goat serum according to the secondary antibody host species for 2 hours and incubated in the first primary antibody at $4^{\circ} \mathrm{C}$ overnight. Sections were then washed in $0.05 \mathrm{M} \mathrm{Tris-} \mathrm{HCl}(\mathrm{pH}$ 7.4) (3 times for 5 minutes each), followed by incubation in the secondary antibody at room temperature for 2 hours and then washing. For double staining, the same procedure was performed with the second primary and secondary antibodies. Sections were mounted on slides and covered with $90 \%$ glycerin for observation under a confocal microscope (FluoView FV1000; Olympus). The dilution of antibodies used included anti-Wnt3a (1:50; Millipore), anti-Fz-1 (1:100; Abgent), anti-Fz-8 (1:100; Bioworld), anti-active $\beta$-catenin (1:200; Millipore), anti-NeuN (1:100 to $1: 200$; Millipore), anti-IL-18 (5 $\mu \mathrm{g} / \mathrm{ml}$; Abnova), anti-c-Fos (1:200; Santa Cruz Biotechnology), anti-GFAP (1:200; Santa Cruz Biotechnology), anti-Iba1 (1:100; Abcam), FITC-conjugated isolectin B4 (1:100; Sigma-Aldrich), anti-CGRP (1:100; Abcam), and anti-MAP2 (1:100; Invitrogen). For nucleus counterstaining, sections were incubated with $100 \mu \mathrm{g} / \mathrm{ml}$ RNase (Thermo Scientific) for 20 minutes at $37^{\circ} \mathrm{C}$, then stained with $300 \mu \mathrm{l}$ propidium iodide.

To obtain quantitative measurements of GFAP and IBA1 immunofluorescence in the DH, 15-20 fields covering the entire DH in each group, which included 20 SC sections from 4 rats, were evaluated and photographed at the same exposure time to generate the raw data. The average green fluorescence intensity of each pixel was normalized to the background intensity in the same image. These protocols were similar to those described previously $(22,54)$. The same methods were used to obtain quantitative measurements of FZ1, FZ8, and $\beta$-catenin immunofluorescence in DRG. A total of 24 DRG sections from 6 ganglia (4 sections from each ganglion; $L_{4}$ and $L_{5}$ ganglia were taken from each of the 3 rats) were included in each group. In the DH, the number of Fos-like immunoreactive neurons in laminae I-VII was determined by averaging the counts made in 20 SC sections for each group (4 rats). In DRG, numbers of the 3 categories of cells - large-, medium-sized, and small - and the proportions of these cells in each category with immunofluorescence stains of WNT3a, FZ1, and FZ8 or FZ8 nuclear transport, were determined by counting 1,200 cells from 6 ganglia (200 cells from each ganglion; $\mathrm{L}_{4}$ and $\mathrm{L}_{5}$ ganglia were taken from each of the 3 rats) in each group.

ChIP. Under anesthesia, the $\mathrm{L}_{4}-\mathrm{L}_{5}$ segments of $\mathrm{SC}$ were removed and disrupted using a glass-glass homogenizer in ice-cold PBS with protease inhibitors and phenylmethylsulfonyl fluoride. The dounced SC was filtrated into a tube through a $100-\mu \mathrm{m}$ cell strainer (Falcon 352360; BD Biosciences) to remove connective tissue. Thirty-seven percent (wt/vol) formaldehyde was then added to the final formaldehyde concentration of $1 \%$ to cross-link proteins to DNA for 30 minutes at room temperature. The cross-linking reaction was stopped by the addition of glycine solution to a final concentration of $0.125 \mathrm{M}$ to quench the formaldehyde. The cells were washed 2 times with PBS at $4{ }^{\circ} \mathrm{C}$. Subsequently, ChIP assays were performed using a Simple ChIP Enzymatic Chromatin IP kit (Cell Signaling Technology) according to the manufacturer's protocol. Immunoprecipitation was performed using an antibody directed against $\beta$-catenin (H-102) (sc-7199; Santa Cruz Biotechnology) 
or using rabbit IgG (Cell Signaling Technology; catalog no. 2729) as a negative control. The promoter sequences of IL-18, IL- $1 \beta$ and TNF- $\alpha$ were identified using the UCSC Rat Genome Browser (http://genome. ucsc.edu/cgi-bin/hgNear?org=Rat\&db=0\&near_order=\&near_count $=$ \&hgsid=226407907). A transcription factor binding site search revealed that the promoter regions of IL-18, IL- $1 \beta$, and TNF- $\alpha$ contain several consensus TCF/LEF binding sites: $5^{\prime}-(\mathrm{A} / \mathrm{T})(\mathrm{A} / \mathrm{T}) \mathrm{CAAAG}-3^{\prime}$ or 5'-CTTTG A/T A/T-3' (IL-18: sites A, C; IL-1 $\beta$ : site A; TNF- $\alpha$ : sites A, C), or putative partial sites (IL-18: site B; IL-1 $\beta$ : -sites B,C; TNF- $\alpha$ : site B) within 3,000 nucleotides upstream from the ATG translation start site. Immunoprecipitated DNA was analyzed using PCR with rat IL-18, IL- $1 \beta$, and TNF- $\alpha$ promoter-specific primers, respectively, that encompassed these TCF/LEF binding sites (Supplemental Table 3). The PCR cycle parameters were $95^{\circ} \mathrm{C}$ for 5 minutes and then 35 cycles at $95^{\circ} \mathrm{C}$ for 30 seconds, $60^{\circ} \mathrm{C}$ for 30 seconds, and $72^{\circ} \mathrm{C}$ for 45 seconds, and a final extension at $72^{\circ} \mathrm{C}$ for 5 minutes. PCR products were resolved by electrophoresis in a $2 \%$ agarose gel and stained with ethidium bromide.

Statistics. SPSS Rel 15 (SPSS Inc.) was used to conduct all statistical analyses. Alterations of detected mRNA and protein expression and the behavioral responses to mechanical and thermal stimuli over time among groups were tested with 1-way and 2-way ANOVA with repeated measures followed by Bonferroni's post-hoc tests, respectively. Individual Student's $t$ tests were used for Western blot data to test specific hypotheses about differences between each operated or drug-treated group and its corresponding control sham-operated or drug-treated group. All data are presented as the mean \pm SEM. The criterion for statistical significance was a $P$ value less than 0.05 .

Study approval. Experimental procedures and animal care and use were performed in accordance with the ethics committee regulations of the International Association for the Study of Pain and approved by the Animal Care and Use Committees of Parker University Research Institute and Peking University Neuroscience Research Institute.

\section{Acknowledgments}

This work was partly supported by Parker Research Foundation (PRF-BSR10110607), the National Natural Science Foundation of China (NSFC81271241, NSFC81000475), and Peking University Health Science Center (BMU20120310).

Received for publication October 10, 2012, and accepted in revised form February 14, 2013.

Address correspondence to: Xue-Jun Song, Department of Neurobiology, Parker University Research Institute, 2540 Walnut Hill Lane, Dallas, Texas 75229, USA, or Neuroscience Research Institute, Peking University, Beijing 100191, China. Phone: 001.972.438.6932, ext. 7144; Fax: 001.214.902.2482; E-mail: song@parker.edu.
1. Ciani L, Salinas PC. WNTs in the vertebrate nervous system: from patterning to neuronal connectivity. Nat Rev Neurosci. 2005;6(5):351-362.

2. Packard M, Koo ES, Gorczyca M, Sharpe J, Cumberledge S, Budnik V. The Drosophila Wnt, wingless, provides an essential signal for pre- and postsynaptic differentiation. Cell. 2002;111(3):319-330.

3. Fuerer C, Nusse R, Ten Berge D. Wnt signalling in development and disease. Max Delbruck Center for Molecular Medicine Meeting on Wnt Signaling in Development and Disease. EMBO Rep. 2008;9(2):134-138.

4. Chen J, Park CS, Tang SJ. Activity-dependent synaptic Wnt release regulates hippocampal long term potentiation. J Biol Chem. 2006;281(17):11910-11916.

5. Shimizu H, Julius MA, Giarre M, Zheng Z, Brown AM, Kitajewski J. Transformation by Wnt family proteins correlates with regulation of beta-catenin. Cell Growth Differ. 1997;8(12):1349-1358.

6. Tu X, et al. Noncanonical Wnt signaling through G protein-linked PKCdelta activation promotes bone formation. Dev Cell. 2007;12(1):113-127.

7. Kestler HA, Kuhl M. Generating a Wnt switch: it's all about the right dosage. J Cell Biol. 2011; 193(3):431-433.

8. Budnik V, Salinas PC. Wnt signaling during synaptic development and plasticity. Curr Opin Neurobiol. 2011;21(1):151-159.

9. Wang Y, et al. The Wnt/beta-catenin pathway is required for the development of leukemia stem cells in AML. Science. 2010;327(5973):1650-1653.

10. Clevers H, Batlle E. EphB/EphrinB receptors and Wnt signaling in colorectal cancer. Cancer Res. 2006;66(1):2-5

11. Liu Y, et al. Repulsive Wnt signaling inhibits axon regeneration after CNS injury. J Neurosci. 2008;28(33):8376-8382.

12. Suh HI, Min J, Choi KH, Kim SW, Kim KS, Jeon SR. Axonal regeneration effects of Wnt3a-secreting fibroblast transplantation in spinal cord-injured rats. Acta Neurochir (Wien). 2011;153(5):1003-1010.

13. Bennett GJ, Xie YK. A peripheral mononeuropathy in rat that produces disorders of pain sensation like those seen in man. Pain. 1988;33(1):87-107.

14. Schwei MJ, et al. Neurochemical and cellular reorganization of the spinal cord in a murine model of bone cancer pain. J Neurosci. 1999; 19(24):10886-10897.

15. Sabino MA, et al. Simultaneous reduction in cancer pain, bone destruction, and tumor growth by selective inhibition of cyclooxygenase-2. Cancer Res. 2002;62(24):7343-7349.

16. Ji RR, Befort K, Brenner GJ, Woolf CJ. ERK MAP kinase activation in superficial spinal cord neurons induces prodynorphin and NK-1 upregulation and contributes to persistent inflammatory pain hypersensitivity. J Neurosci. 2002;22(2):478-485.

17. Park JS, et al. Persistent inflammation induces GluR2 internalization via NMDA receptor-triggered PKC activation in dorsal horn neurons. JNeurosci. 2009;29(10):3206-3219.

18. Wisniewska MB, et al. LEF1/beta-catenin complex regulates transcription of the Cav3.1 calcium channel gene (Cacna1g) in thalamic neurons of the adult brain. J Neurosci. 2010;30(14):4957-4969.

19. Chen B, et al. Small molecule-mediated disruption of Wnt-dependent signaling in tissue regeneration and cancer. Nat Chem Biol. 2009;5(2):100-107.

20. DeAlmeida VI, Miao L, Ernst JA, Koeppen H, Polakis $\mathrm{P}$, Rubinfeld B. The soluble wnt receptor Frizzled8CRD-hFc inhibits the growth of teratocarcinomas in vivo. Cancer Res. 2007;67(11):5371-5379.

21. Osada T, et al. Antihelminth compound niclosamide downregulates Wnt signaling and elicits antitumor responses in tumors with activating APC mutations. Cancer Res. 2011;71(12):4172-4182.

22. Liu S, et al. Blocking EphB1 receptor forward signaling in spinal cord relieves bone cancer pain and rescues analgesic effect of morphine treatment in rodents. Cancer Res. 2011;71(13):4392-4402.

23. Wu XF, Liu WT, Liu YP, Huang ZJ, Zhang YK, Song XJ. Reopening of ATP-sensitive potassium channels reduces neuropathic pain and regulates astroglial gap junctions in the rat spinal cord. Pain. 2011;152(11):2605-2615.

24. Plater-Zyberk C, et al. Therapeutic effect of neutralizing endogenous IL-18 activity in the collagen-induced model of arthritis. J Clin Invest. 2001;108(12):1825-1832.

25. Boraschi D, Dinarello CA. IL-18 in autoimmunity: review. Eur Cytokine Netw. 2006;17(4):224-252.

26. Miyoshi K, Obata K, Kondo T, Okamura H,
Noguchi K. Interleukin-18-mediated microglia/ astrocyte interaction in the spinal cord enhances neuropathic pain processing after nerve injury. J Neurosci. 2008;28(48):12775-12787.

27. Nelson WJ, Nusse R. Convergence of Wnt, beta-catenin, and cadherin pathways. Science. 2004;303(5663):1483-1487.

28. Ftouh S, Akbar MT, Hirsch SR, de Belleroche JS. Down-regulation of Dickkopf 3, a regulator of the Wnt signalling pathway, in elderly schizophrenic subjects. J Neurochem. 2005;94(2):520-530.

29. Nishimura M, et al. Presenilin mutations associated with Alzheimer disease cause defective intracellular trafficking of beta-catenin, a component of the presenilin protein complex. Nat Med. 1999;5(2):164-169.

30. Caricasole A, et al. Induction of Dickkopf-1, a negative modulator of the Wnt pathway, is associated with neuronal degeneration in Alzheimer's brain. J Neurosci. 2004;24(26):6021-6027.

31. Novikova SI, He F, Bai J, Lidow MS. Neuropathology of the cerebral cortex observed in a range of animal models of prenatal cocaine exposure may reflect alterations in genes involved in the Wnt and cadherin systems. Synapse. 2005;56(2):105-116.

32. Fernandez-Martos CM, Gonzalez-Fernandez C, Gonzalez P, Maqueda A, Arenas E, Rodriguez FJ. Differential expression of Wnts after spinal cord contusion injury in adult rats. PLoS One. 2011;6(11):e27000.

33. Koval A, Katanaev VL. Wnt3a stimulation elicits G-protein-coupled receptor properties of mammalian Frizzled proteins. Biochem J. 2011;433(3):435-440.

34. Kestler HA, Kuhl M. From individual Wnt pathways towards a Wnt signalling network. Philos Trans R Soc Lond B Biol Sci. 2008;363(1495):1333-1347.

35. Mathew D, Ataman B, Chen J, Zhang Y, Cumberledge S, Budnik V. Wingless signaling at synapses is through cleavage and nuclear import of receptor DFrizzled2. Science. 2005;310(5752):1344-1347.

36. Anson $\mathrm{M}$, et al. Oncogenic beta-catenin triggers an inflammatory response that determines the aggressiveness of hepatocellular carcinoma in mice. J Clin Invest. 2012;122(2):586-599.

37. Song XJ, Cao JL, Li HC, Zheng JH, Song XS, Xiong LZ. Upregulation and redistribution of ephrinB 
and EphB receptor in dorsal root ganglion and spinal dorsal horn neurons after peripheral nerve injury and dorsal rhizotomy. Eur J Pain. 2008;12(8):1031-1039.

38. Song XJ, Zheng JH, Cao JL, Liu WT, Song XS, Huang ZJ. EphrinB-EphB receptor signaling contributes to neuropathic pain by regulating neural excitability and spinal synaptic plasticity in rats. Pain. 2008;139(1):168-180.

39. Han Y, Song XS, Liu WT, Henkemeyer M, Song $\mathrm{XJ}$. Targeted mutation of EphB1 receptor prevents development of neuropathic hyperalgesia and physical dependence on morphine in mice. $\mathrm{Mol}$ Pain. 2008;4:60

40. Liu WT, Li HC, Song XS, Huang ZJ, Song XJ. EphB receptor signaling in mouse spinal cord contributes to physical dependence on morphine. FASEB J. 2009;23(1):90-98

41. Krull CE, et al. Interactions of Eph-related receptors and ligands confer rostrocaudal pattern to trunk neural crest migration. Curr Biol. 1997;7(8):571-580

42. Wang HU, Anderson DJ. Eph family transmem- brane ligands can mediate repulsive guidance of trunk neural crest migration and motor axon outgrowth. Neuron. 1997;18(3):383-396

43. Wilkinson DG. Eph receptors and ephrins: regulators of guidance and assembly. Int Rev Cytol. 2000;196:177-244.

44. Wilkinson DG. Multiple roles of EPH receptors and ephrins in neural development. Nat Rev Neurosci. 2001;2(3):155-164.

45. Salinas PC, Zou Y. Wnt signaling in neural circuit assembly. Annu Rev Neurosci. 2008;31:339-358.

46. Zou Y. Wnt signaling in axon guidance. Trends Neu rosci. 2004;27(9):528-532.

47. Batlle E, et al. Beta-catenin and TCF mediate cell positioning in the intestinal epithelium by controlling the expression of EphB/ephrinB. Cell. 2002;111(2):251-263.

48. Batlle E, et al. EphB receptor activity suppresses colorectal cancer progression. Nature. 2005; 435(7045):1126-1130.

49. Song XJ, Hu SJ, Greenquist KW, Zhang JM, LaMotte RH. Mechanical and thermal hyperalgesia and ectopic neuronal discharge after chronic compression of dorsal root ganglia. J Neurophysiol. 1999;82(6):3347-3358

50. Song XJ, Wang ZB, Gan Q, Walters ET. cAMP and cGMP contribute to sensory neuron hyperexcitability and hyperalgesia in rats with dorsal root ganglia compression. J Neurophysiol. 2006;95(1):479-492.

51. Luger NM, et al. Osteoprotegerin diminishes advanced bone cancer pain. Cancer Res. 2001; 61(10):4038-4047.

52. Sabino MA, Luger NM, Mach DB, Rogers SD, Schwei MJ, Mantyh PW. Different tumors in bone each give rise to a distinct pattern of skeletal destruction, bone cancer-related pain behaviors and neurochemical changes in the central nervous system. Int J Cancer. 2003;104(5):550-558.

53. Hattori S, Li Q, Matsui N, Nishino H. Treadmill running test for evaluating locomotor activity after 6-OHDA lesions and dopaminergic cell grafts in the rat. Brain Res Bull. 1993;31(3-4):433-435.

54. Liu WT, Han Y, Liu YP, Song AA, Barnes B, Song XJ. Spinal matrix metalloproteinase- 9 contributes to physical dependence on morphine in mice. J Neurosci. 2010;30(22):7613-7623. 